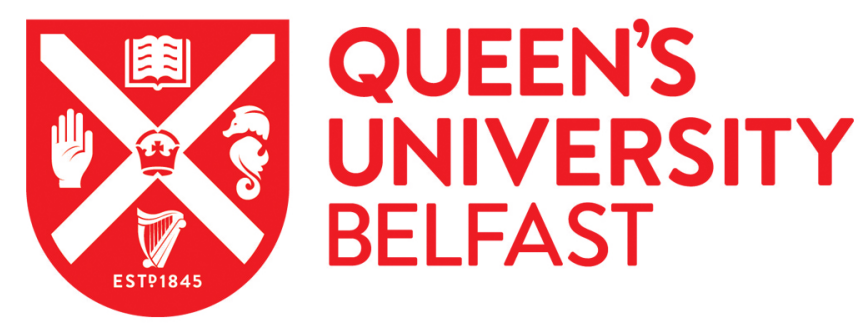

\title{
Majority group belonging without minority group distancing? Minority experiences of intergroup contact and inequality
}

Kende, J., Baysu, G., Van Laar, C., \& Phalet, K. (2021). Majority group belonging without minority group distancing? Minority experiences of intergroup contact and inequality. British Journal of Social Psychology, $60(1), 121-145$. https://doi.org/10.1111/bjso.12382

Published in:

British Journal of Social Psychology

Document Version:

Peer reviewed version

Queen's University Belfast - Research Portal:

Link to publication record in Queen's University Belfast Research Portal

Publisher rights

(c) 2020 The British Psychological Society. This work is made available online in accordance with the publisher's policies. Please refer to any applicable terms of use of the publisher.

\section{General rights}

Copyright for the publications made accessible via the Queen's University Belfast Research Portal is retained by the author(s) and / or other copyright owners and it is a condition of accessing these publications that users recognise and abide by the legal requirements associated with these rights.

Take down policy

The Research Portal is Queen's institutional repository that provides access to Queen's research output. Every effort has been made to ensure that content in the Research Portal does not infringe any person's rights, or applicable UK laws. If you discover content in the Research Portal that you believe breaches copyright or violates any law, please contact openaccess@qub.ac.uk. 


\title{
"Majority group belonging without minority group distancing? Minority experiences of intergroup contact and inequality" \\ Judit Kende, University of Lausanne
}

Gülseli Baysu, Queens University Belfast

Karen Phalet \& Colette Van Laar, KU Leuven

Accepted for publication in British Journal of Social Psychology

\begin{abstract}
As most immigrant-origin minority youth grow up in ethnically diverse social worlds, they develop a sense of belonging to both the national majority and the ethnic minority group. Our study adds to a growing body of research on minority experiences of intergroup contact by (a) including both minority and majority group belonging as outcomes; and (b) examining the interplay of majority contact with unequal treatment. We surveyed 1200 Turkish and Moroccan Belgian minority youth in 315 classrooms across 65 schools, using multiple measures of intergroup contact, unequal treatment in school, and minority and majority group belonging. Multi-level models showed that minority youth who experienced more intergroup contact, and less unequal treatment, reported more belonging to the majority group. In addition, contact predicted less belonging to the minority group only in the presence of unequal treatment: for minority youth who perceived less unequal treatment, either individually or collectively, intergroup contact was unrelated to minority group belonging. We conclude that majority group contact and belonging need not come at the cost of minority group distancing in the absence of inequality.
\end{abstract}


MINORITY CONTACT AND INEQUALITY

"I remember being about 9 years old, at a girl's birthday, where hotdogs were served. I asked the parents what kind of meat the hotdogs were. They replied by asking me why that would be relevant. I told them, I couldn't eat pork because I am a Muslim. The father started laughing out loud saying that me and my sand nigger family should adapt to life and customs in Belgium, after which they tried to force me to eat the pork hotdogs.... When I was still little, being confronted with so much racism ... and going to an elementary school which used to be predominantly white, I started to feel ashamed of being half Moroccan. ... I didn't want to be associated with Arabs or Muslims. I wanted to be seen as fully Belgian and white. I wouldn't tell my classmates I was actually half Moroccan. ... I feel sad for having done this, but when you're just a kid, all you want to do is to fit in." The project "Everyday racism" collected stories about minority experiences of intergroup contact and belonging in Belgium (Stand Against Racism, 2015). Minority youth inhabit ethnically diverse social worlds and develop feelings of belonging to both the minority and the majority group (Berry, 2001; Deaux \& Verkuyten, 2014). As the quote from a Moroccan Belgian woman shows, her sense of belonging is informed by her day-to-day experiences of intergroup interactions. Those interactions can be positive (e.g., being invited to the birthday party of a majority friend) as well as negative (e.g., being ridiculed or humiliated because of one's minority identity). The present paper articulates a minority perspective on the interplay of friendly intergroup contact with negative experiences of unequal intergroup relations. Our main research question concerns the associations of these intergroup experiences with minorities' sense of belonging to both the majority group and the minority group.

The quote exemplifies the phenomenon of minority group distancing in response to the potential for discrimination that comes with majority contact for Muslim minority youth in the Belgian intergroup context. On the one hand, there is extensive evidence relating positive 
intergroup contact to more harmonious intergroup relations. On the other hand, critical contact research suggests a possible downside of intergroup contact for minorities, when friendly contact perpetuates unequal intergroup relations through undermining minority group belonging (Dixon, Levine, Reicher, \& Durrheim, 2012; Hässler et al., 2020). While there is preliminary evidence linking minority engagement in intergroup contact to some aspects of minority-group distancing, findings are mixed (Becker, Wright, Lubensky, \& Zhou, 2013; Kamberi, Martinovic, \& Verkuyten, 2017; Reimer et al., 2016). Against this background, we ask how minority experiences of intergroup contact inform their feelings of belonging to both the majority and the minority group. To shed light on mixed findings of minority group distancing, we investigate the role of persistent inequality in many intergroup contexts ([BLINDED]). In particular, we argue that minority experiences of unequal treatment might pit positive majority relations against their sense of belonging to the minority group. If this would be the case, the upside should be that when the intergroup context ensures equal treatment majority contact need not come with minority group distancing.

\section{Belonging to both the majority and minority group}

From the perspective of social identity performance, intergroup contexts define group identities through the social validation and valuation of group membership in interactions among group members (Klein, Spears, \& Reicher, 2007). In particular, minority group members negotiate their belonging to both majority and minority groups in interactions within and across both groups. For minorities to develop a secure sense of belonging to both groups, therefore, the intergroup context should affirm the value ([BLINDED]) and support the interactive performance of both group identities (Klein et al., 2007). By implication, minorities' psychological sense of belonging to both minority and majority groups depends 
critically on their experiences of intergroup contact (Deaux \& Verkuyten, 2014;

[BLINDED]).

Not only majority group belonging, but also belonging to the minority group and their combination, are significant parts of minorities' social world and sense of self. Moreover, both minority and majority group belonging come with unique psychological benefits. Thus, the national majority belonging of immigrant origin persons is associated with enhanced status attainment, access to resources, and a sense of recognition (Kanas, van Tubergen, \& van der Lippe, 2011; Noguera, 2004). Moreover, majority belonging predicts the democratic attitudes and civic engagement of minority citizens ([BLINDED]). In parallel, minority persons who maintain close ties with the minority ethnic or racial group receive more social support and derive more positive self-worth (Branscombe, Fernandez, Gomez, \& Cronin, 2012; Van Laar, Bleeker, Ellemers, \& Meijer, 2014). In addition, the combination of majority and minority group belonging can uniquely predict minority adjustment and achievement outcomes ([BLINDED]; Nguyen \& Benet-Martinez, 2013). Accordingly, the social reality of most immigrant-origin youth is anchored in their belonging to both the national majority and the ethnic minority groups. Therefore, our study looks beyond a predominant focus on either ethnic or national orientations in previous contact studies ([BLINDED]) and includes both minority (ethnic) and majority (national) group belonging as critical outcomes of intergroup contact for minority persons.

\section{Majority group belonging: positive majority contact and unequal treatment}

In their daily social contact with majority group members, most minority youth have positive experiences of friendly interactions as well as negative experiences of unequal treatment ([BLINDED]; Tropp, 2007). In line with social identity research ([BLINDED]), unequal treatment induces identity threat by communicating to minorities that they are not accepted as fellow majority group members. Conversely, positive majority contact conveys 
identity valuation through including minorities as fellow group members. These negative and positive contact experiences jointly inform minorities' sense of belonging to the majority group ([BLINDED]).

There is converging evidence that minority individuals feel more belonging to the majority group when they have more positive contact with majority group members, in particular when they have more majority friends (Davies, Tropp, Aron, Pettigrew, \& Wright, 2011; Tropp, 2006). For example, immigrant-origin minority youth in the Netherlands who had more majority friends were more identified with the majority Dutch group (Munniksma, Verkuyten, Flache, Stark, \& Veenstra, 2015). Longitudinal findings provide further support for bidirectional relations between majority friendship and majority belonging (Leszczensky, Stark, Flache, \& Munniksma, 2016).

At the same time, minority persons across countries feel less belonging to the majority group when they experience discrimination. Such unequal treatment communicates to them that they do not fully and equally belong to the majority group (Hutchison, Lubna, GoncalvesPortelinha, Kamali, \& Khan, 2015; Jasinskaja-Lahti, Liebkind, \& Solheim, 2009). Along those lines, perceptions of discrimination predict weaker majority group belonging in devalued immigrant-origin minorities: For example, Turkish and Moroccan immigrant-origin minorities in Belgium, Sweden and the Netherlands who reported some personal experience of discrimination, evaluated the majority group less positively and identified less strongly with the majority group (Fleischmann \& Phalet, 2016). Similarly, more general perceptions of inequality also weakened majority belonging, for instance, among Dutch Muslim youth (Thijs, Hornstra, \& Charki, 2018). Especially when experiences of unequal treatment are shared among minority group members, they may undermine the majority belonging of minority persons - even in the absence of individual negative experiences (Major \& O’Brien, 2005). Again, this association probably works both ways - as when lower majority belonging 
of minority group members fuels more negative intergroup experiences with majority group members in recursive cycles of mutual distancing (Roblain, Azzi, \& Licata, 2016).

Overall, we expect that with more positive contact, minority youth will feel more belonging to the majority group, i.e., more positive attitudes and stronger self-identification (Hypothesis 1a). In contrast, with more unequal treatment, minority youth are expected to feel less belonging, i.e., less positive attitudes and weaker self-identification (Hypothesis 1b). Moreover, there is some evidence relating positive contact to stronger majority group belonging for minority group members, even in the presence of discrimination experiences (Mähönen \& Jasinskaja-Lahti, 2016; Thomsen \& Rafiqi, 2016). In view of consistently positive associations of majority contact with majority group belonging in previous research, we do not expect significant moderation by unequal treatment. However, non-significant interactions would further strengthen generally positive contact effects on majority belonging.

\section{Minority group distancing: the interplay of positive contact and unequal treatment}

Whereas the benefits of positive contact with majority peers are well documented for majority group belonging, less is known about minority group belonging. From a social identity performance approach, belonging to the minority group is neither inherent in the ethnic origin of minority youth nor fixed by their immigrant parentage (Klein et al., 2007). Rather, their belonging is contingent on the expression and validation of a distinct minority group identity in intergroup interactions (Klein et al, 2007; [BLINDED]). When the intergroup context ignores or rejects the minority identity of immigrant minority youth, it leaves them struggling to square this minority identity with majority group belonging (Azzi, 2010; Fleischmann \& Phalet, 2016).

The grounding of minority group belonging in intergroup interactions receives some support from critical contact research, which exposed distancing from the minority group as a potential downside of friendly intergroup contact (Dixon et al., 2012; Hässler et al., 2020). 
Thus, minority persons with more majority contact were found to downplay their minority identity, discount discrimination against their minority group, or perceive other minority group members as less deserving (Cakal, Hewstone, Schwär, \& Heath, 2011; Derks, Van Laar, Ellemers, \& Raghoe, 2015, [BLINDED]). For example, Dutch Muslim minorities who had more majority contact reported significantly weaker religious minority identification and attitudes (Maliepaard \& Phalet, 2012). Other studies, however, found no evidence of minority group distancing with more positive majority contact (Reimer et al., 2016; Reimer, Schmid, Love, \& Hewstone, 2019). Thus, Roma minority persons in Macedonia did not endorse more negative attitudes towards Roma with more non-Roma contact (Kamberi et al., 2017). In light of mixed findings of either negative or null associations of intergroup contact with minority group distancing, we do not propose a main effect hypothesis associating positive intergroup contact with minority group distancing.

Turning to minority experiences of unequal treatment, stigma researchers similarly found mixed evidence of minority group distancing (Derks et al., 2016, 2015; Iyer \& Ryan, 2009). For example, when Hindustani-origin workers in the Netherlands were reminded of the unequal treatment their minority group faces, they distanced themselves from the minority group and evaluated Hindustanis less positively (Derks et al., 2015). To the contrary, and in line with an alternate rejection-identification hypothesis, other studies found enhanced minority group belonging in response to unequal treatment (Branscombe, Ellemers, Spears, \& Doosje, 1999; Fleischmann et al., 2011). For example, Black Americans self-identified more strongly as Black when they had experienced more racial discrimination (Branscombe et al, 1999); and Dutch Muslim minorities were more strongly identified and more supportive of religious rights when they perceived more group discrimination (Fleischmann et al., 2011). While the aforementioned studies focused on individual experiences of discrimination, collective experiences of discrimination can make a difference over and beyond personal 
discrimination experiences (Bourguignon, Seron, Yzerbyt, \& Herman, 2006; Major \& O'Brien, 2005). Even in the absence of personal experiences of unequal treatment, minority perceptions of group discrimination may also be related to minority identification. Because there is evidence on both sides of the ledger, so that minority persons may either distance themselves from the minority group or rally around their minority identity in response to unequal treatment, we will explore the association between minority belonging and unequal treatment without proposing a specific hypothesis.

In view of mixed findings on minority group distancing from separate streams of research on intergroup contact and stigma, we focus on the interplay of positive contact with unequal treatment; and we propose that they jointly make the difference between minority group belonging or distancing. As the opening quote from a Moroccan-Belgian girl recalls (cf. supra), she learned at the birthday party of a majority Belgian friend to downplay her Moroccan minority identity as a way to protect her self-worth in an unequal intergroup context. Her experience situates minority group distancing at the intersection of positive majority contact (being invited to a friend's party) with unequal treatment (being made to eat pork as a Muslim). The present study aims to shed light on mixed findings of minority group distancing in intergroup interactions by examining the interplay of minority experiences of friendly majority contact with unequal treatment. We expect that with more positive majority contact, minority youth will feel less minority group belonging, i.e., less positive attitudes and weaker self-identification, only in the presence of unequal treatment. Furthermore, we expect that with more positive majority contact minority youth will distance themselves from the minority group when they experience unequal treatment either individually or collectively. (Hypothesis 2).

\section{Method}




\section{Participants \& Procedure}

Data were collected between 2012-2013 as part of the large-scale Belgian CILS Study (data available upon email request to first author) (Emonds, Meeus, Heikamp, \& Meuleman, 2015). The Belgian CILS data is part of a larger European CILS surveying representative samples of pupils in Belgium, Germany, Sweden, the Netherlands and the United Kingdom (www.CILS4.eu). Secondary schools were randomly sampled across Belgium-Flanders using a stratified sampling design which ensured oversampling more ethnically diverse schools (CILS4EU, 2016). After obtaining ethical clearance from the school principal and parental and teacher consent, all eligible students in 63 schools in 315 classrooms in Flanders-Belgium completed a survey during class hours. Within each school, participants were randomly sampled from the first (29\%), second (32\%), and third (39\%) year of secondary school.

For the current analyses, we selected Turkish and Moroccan origin minority students $(N=1251,52 \%$ boys, Mage $=15.06$ years $)$ because they are the two major and most disadvantaged and devalued Muslim minority groups in Belgium (Phalet \& Swyngedouw, 2003). Moreover, as public discourse and politicians regularly pit Muslim and European values against each other, the dual belonging of Muslim minorities especially is questioned in Western Europe (Alba \& Holdaway, 2013). Turkish or Moroccan heritage was defined based on self-reported parentage with at least one parent or grandparent born in Turkey or Morocco. Participants' ages ranged from 13 to 18 years. Most participants (80\%) were secondgeneration, that is, born in Belgium with one or both parents born in Morocco or Turkey, as is typical of these groups in Western Europe. First- and third-generation participants were smaller in number (16\% and $4 \%$ respectively).

\section{Measures}

Positive majority contact was measured as the average score of 3 items referring to positive contact experiences in the form of friendship and voluntary contact, e.g. 'How many 
of your friends have a Belgian background" (1-some to 5-almost all or all) and "How often do you spend time during your school break with peers with a Belgian background?" "How often do you spend time in the neighbourhood where you live with peers with a Belgian background? (1-never to 5-every day) (CILS4EU, 2016), $\alpha=.75, M=2.83, S D=1.23$.

We used two measures of unequal treatment in school to distinguish experiences of discrimination from more general perceptions of unfair treatment in school. Furthermore, we specified both measures of unequal treatment at the individual level of minority participants and at the collective level of their minority peers within the same class. The latter constitutes a more external contextual measure of unequal treatment within classrooms as intergroup contexts.

Experiences of discrimination were measured with one item: "How often are you discriminated against, treated unfairly or with hostility at school?" (CILS4EU, 2016). Answers were given on a 4-point scale, from (after recoding) 1 (never) to 4 (almost always), $M=1.32, S D=0.66$. As distinct from individual experiences of discrimination, we assessed collective discrimination experiences by aggregating (averaging) individual ratings over all Turkish and Moroccan minority students (based on their parentage) within each classroom.

Perceived unfair treatment was a composite of two items: "The rules are applied equally to all students (reverse coded)" and "Some students are allowed to do more than others" ([BLINDED]). Answers were given on a 5-point Likert scale, from 1 (strongly disagree) to 5 (strongly agree), $r=.40, M=2.43, S D=0.99$. In addition to individual perceptions, collective perceptions of unfairness were measured by aggregating individual ratings over all Turkish and Moroccan minority students (based on their parentage) within each classroom. 
To distinguish between evaluative and affective components of belonging to the majority group, we used two measures: attitudes towards the majority group and strength of majority identification (Ashmore, Deaux, \& McLaughlin-Volpe, 2004)

Attitude towards the majority group was measured with a feeling thermometer: 'Please rate how you feel about the following groups in Belgium on a scale that runs from 0 to 100. The higher the number, the more positive you feel, and the lower the number the more negative you feel towards this group'. Attitude towards the majority group was then measured with feelings towards "Belgians" (CILS4EU, 2016), $M=65.79, S D=24.07$.

Strength of majority identification was measured with two items 'How strongly do you feel Belgian?' and “How strongly do you feel Flemish?' (CILS4EU, 2016). Answers were given on a 5-point scale, from 1 (not at all) to 5 (very strongly), $M=2.98, S D=1.33$.

Similarly, we used two measures for distinct evaluative and affective components of belonging to the minority group: attitudes towards the minority group and strength of minority identification.

Attitude towards the minority group was measured with the same feeling thermometer as attitudes towards the majority group (CILS4EU, 2016): 'Please rate how you feel towards the following groups in Belgium'. For adolescents of Turkish origin, this evaluation referred to "Turks" whereas for those of Moroccan origin to "Moroccans", $M=$ 89.91, $S D=19.18$

Strength of minority identification was measured with two questions. First participants reported their group membership(s) in response to the question: "Some people feel that they are members of several groups. Which, if any, of the following groups are you a member of?' In addition to the Belgian or Flemish majority groups, participants could choose several minority groups, including Turks or Kurds as minority identities for Turkish Belgians and Moroccans or Berbers as minority identities for Moroccan Belgians. Next, participants 
rated how important this minority identity was for them: "How strongly do you feel you belong to this group?" Answers were given on a 4-point scale, ranging from 1 (very weakly) to 4 (very strongly). When they had selected more than one identity (e.g., both Kurdish and Turkish), they were asked to think of the minority group that they felt most strongly about while rating the importance of their ethnic identity (CILS4EU, 2016). When they had not selected or rated any minority identity in the list (neither as Turk, Kurd, Berber, nor Moroccan), they were assigned the lowest score of $1 . M=2.88, S D=1.26$.

Controls. As control variables we included participant's age (range $12.6-17.9, M=$ $15.06, S D=1.15)$ and gender $(0=$ male, $1=$ female $)$ and the ethnic composition of the classroom (percentage of Turkish and Moroccan origin students in participants' class - based on their parentage, range $4 \%-100 \%, M=0.49, S D=0.39)$.

See Table 1 for correlations.

\section{Analytic strategy}

Using Mplus 7 (Muthén \& Muthén, 1998-2012), a series of separate two-level regression analyses were conducted to test hypothetical associations of positive majority contact and either personal experiences of discrimination or perceptions of unfair treatment as a measure of unequal treatment with either attitudes or strength of identification as outcome measures of both majority and minority group belonging (Muthén \& Muthén, 1998-2012). Weak yet significant correlations between attitudes and strength of identification for both the majority group and the minority group (see Table 1) suggest that both measures tap into related yet clearly distinct components of belonging to both groups. Similarly, a significant but low correlation between experiences of discrimination and unfair treatment suggests that both measures refer to related yet distinct constructs (see Table 1). These correlations informed our decision to run four separate individual-level models for both majority and minority group belonging, thus replicating our findings with two different outcome measures 
of belonging and with two different measures of unequal treatment as individual-level predictors. Multi-level analysis was required because of the nested data structure of students (individual level) within classes (class level). ${ }^{1}$ In these main analyses, all predictors were defined at the individual level except for the control variable ethnic composition, which was specified at the class level.

To test Hypotheses 1, two sets of multilevel regression analyses were run for both majority-related measures of belonging. Both sets of analyses tested the expected associations of majority contact (H1a) and of unequal treatment (in separate sets of models for experienced discrimination and perceived unfair treatment) (H1b) as individual-level predictors, with attitudes towards the majority and with strength of majority identification as dependent measures. The interactions between contact and unequal treatment were also explored. The analyses were run in consecutive steps (Hox, Moerbeek, \& van de Schoot, 2010; Tabachnick $\&$ Fidell, 2013). Below we report the regression estimates from the main effects models, but only final models with interactions are fully reported here (see Supplemental Materials for more details). To support Hypothesis 1, significant positive associations between majority contact and our majority belonging measures would be required (H1a), as well as significant negative associations between unequal treatment and majority belonging ( $\mathrm{H} 1 \mathrm{~b})$.

To investigate Hypothesis 2, two sets of multilevel regression analyses were run for both minority-related measures of belonging. Both sets of analyses associated majority contact as the main predictor with attitudes towards the minority group and minority identification as dependent measures, with either experiences of discrimination or perceived

\footnotetext{
${ }^{1}$ As the sample size does not allow for including both school and classroom levels in the same model, we opted for only including the classroom level. We chose to focus on classrooms as the relevant level of intergroup context for our purposes because intergroup interactions with class teachers and classmates are most directly consequential for students (see e.g. Hughes \& Chen, 2011). The partitioning of the variance supported this reasoning: the outcome variables overall had more variance at the class level than at the school level; and only ethnic identification had significant variance at the school level (see Supplemental Materials for breakdown of variance).
} 
unfair treatment as hypothetical individual-level moderators. We also explored the main effects of both measures of unequal treatment on minority group attitudes and identification. These analyses were also run in consecutive steps following the same sequence as Hypothesis 1, see Supplemental Materials. To support Hypothesis 2, significant interaction effects of positive majority contact with experienced discrimination and perceived unfair treatment on our measures of minority belonging would be required. More precisely, we predict significant negative simple effects of majority contact on minority belonging measures only at higher levels of our individual-level measures of unequal treatment.

In addition, we replicated the same analyses for $\mathrm{H} 2$ with collective experiences of unequal treatment by the minority group within classrooms as intergroup contexts. By aggregating individual ratings over minority students at the classroom level, we obtained contextual measures of minority experiences of discrimination and perceptions of unfair treatment. These additional analyses duplicated the same series of four separate models for minority group belonging with our contextual measures of unequal treatment (while controlling for the corresponding individual measures). We also explored main effects of both individual and contextual measures of unequal treatment on minority belonging.

\section{Results}

\section{Majority group belonging: positive majority contact and unequal treatment}

Models with individual experiences of discrimination. In line with $\mathrm{H} 1 \mathrm{a}$ on positive contact and majority belonging, when Turkish or Moroccan minority youth had more contact with majority Belgians, their attitudes towards Belgians were more positive and their majority identification was stronger. In addition, contact effects were positive regardless of discrimination experiences. Conversely, in line with $\mathrm{H} 1 \mathrm{~b}$ on unequal treatment and majority belonging, when they personally experienced more discrimination in school, their attitudes towards majority Belgians were more negative. Discrimination experiences were unrelated to 
their majority identification, however. Together, these results offer support for Hypothesis 1 on majority group belonging (see Table S3 in Supplemental Materials).

Models with individual perceptions of unfair treatment. Models with general perceptions of unfair treatment yielded similar findings. Confirming H1a, majority contact positively predicted the attitudes of minority youth towards majority Belgians as well as their majority identification. In addition, contact effects were positive regardless of perceived unfair treatment. In line with $\mathrm{H} 1 \mathrm{~b}$, when minority youth perceived more unfair treatment in school, their attitudes towards the majority were more negative and their majority identification was weaker. These findings fully support Hypothesis 1 on majority group belonging (see Table 2).

Importantly, positive contact effects were roughly twice the size of the negative effects of (both measures of) unequal treatment (roughly 10 times the standard error). This implies that significant negative effects of unequal treatment (up to 4 times the standard error) never cancel out net gains in majority group belonging with more majority contact. Note that the main effects were the same in the models without the interaction term.

\section{Minority group distancing: the interplay of majority contact with unequal treatment} (individual level)

Models with individual experiences of discrimination. Turning to $\mathrm{H} 2$ on minority group distancing, we tested the same models with majority contact and experiences of discrimination. When Turkish or Moroccan minority youth had more majority contact, their attitudes towards Turks or Moroccans were less positive and they identified less strongly with their minority group. Furthermore, when they experienced more discrimination in school, their attitudes towards their minority group were also more negative, yet their minority identification was not affected (see Table S3). 
. Moreover, in line with $\mathrm{H} 2$ on minority group distancing, there was a significant twoway interaction of positive majority contact with individual discrimination experiences on attitudes towards the minority group (see Table S3). To interpret the interaction, we tested simple effects of majority contact at high vs. low levels of experienced discrimination, and of discrimination at high vs. low levels of contact (+/-1 SD) with the Wald test, which is similar to a z-test. While more majority contact predicted significantly less positive attitudes towards the minority group at higher levels of discrimination $(p<.001)$, this association was not significant when minorities experienced less discrimination $(p=.641)$ (see Figure 1).

Likewise, attitudes towards the minority group were less positive when minorities experienced more discrimination at higher levels of majority contact $(p=.002)$, but at lower levels of majority contact minority attitudes were unrelated to their discrimination experiences $(p=.594)$. Analysis of the region of significance showed that majority contact was significantly related to less positive attitudes towards the minority group for those who scored above 1.2 on experienced discrimination (range 1-4), i.e., for all students who reported at least some personal experience in school (that is, $23.4 \%$ of our minority sample).

\section{FIGURE 1 ABOUT HERE}

For minority identification as the outcome measure, the expected interaction effect did not reach significance (see Table 2), nor did the interaction model significantly improve model fit over the main effects model (see Table S1 in online supplemental materials). We conclude that our findings with individual experiences of discrimination partially support $\mathrm{H} 2$ on minority group distancing.

Models with individual perceptions of unfair treatment. Also for general perceptions of unfair treatment in school, more majority contact predicted less positive attitudes and weaker minority identification. Similarly, when minority youth perceived more unfair treatment in school, their attitudes towards the minority group were less positive (see Table 
2). Their minority identification was unrelated to perceived unfair treatment, however. Note that the main effects were the same in the models without the interaction term.

To replicate $\mathrm{H} 2$ on minority group distancing, we tested the same interaction models with the measure of perceived unfair treatment. In line with $\mathrm{H} 2$, and replicating the findings with personal experiences of discrimination, the interaction effect of majority contact and perceived unfair treatment was significant on minority attitudes. Examining this interaction further (see Figure 2), more majority contact predicted significantly less positive attitudes towards the minority group at higher levels of perceived unfairness $(p=.003)$, yet minority attitudes were unrelated to majority contact when minority youth perceived less unfair treatment $(p=.526)$. Likewise, when minority youth perceived more unfair treatment, their attitudes were significantly less positive only at higher levels of majority contact $(p=.003)$, yet at lower levels of majority contact minority attitudes were unrelated to perceived unfair treatment $(p=.649)$. Analysis of the region of significance showed that majority contact was significantly related to less positive attitudes towards the minority group for those who scored higher than 2.0 on perceived unfair treatment (range 1 to 5); i.e., for all students who did not disagree; more than half our minority samples (60\%) scored above this level.

\section{FIGURE 2 ABOUT HERE}

The same interaction was also significant on strength of minority identification (see Table 2). As Figure 3 shows, more majority contact was significantly related to weaker minority identification at higher levels of perceived unfair treatment in school $(p<.001)$, yet majority contact was unrelated to minority identification when minority students perceived less unfairness $(\mathrm{p}=.182)$. Also, at high levels of majority contact, majority contact was related to weaker minority identification, although this association did not quite reach significance $(p=.070)$. Analysis of the region of significance showed that more majority contact was significantly related to weaker minority identification for those who scored over 
1.74 on unfair treatment (range 1 to 5); $60 \%$ of our minority sample scored above this level. We conclude that the findings with individual perceptions of unfair treatment provide further partial support for $\mathrm{H} 2$ on minority group distancing.

FIGURE 3 ABOUT HERE

Minority group distancing: the interplay of majority contact with collective experiences of unequal treatment (contextual level)

Models with collective minority experiences of discrimination as a contextual moderator. Significant cross-level interactions of majority contact with our contextual measure of collective discrimination experiences by minority students at the classroom level were found, so that majority contact negatively predicted minority attitudes when other minority students in class experienced more discrimination (regardless of individual experiences). This interaction pattern conceptually replicates our individual-level findings in line with $\mathrm{H} 2$ on minority group distancing (see Table 3 and Figure 4). Looking at simple effects, the expected pattern did not reach significance, however: in classrooms with lower levels of collective experiences of discrimination, more majority contact predicted nearsignificantly more positive minority attitudes than in classrooms with more collective experiences of discrimination $(p=.090)$. For minority identification as outcome measure, a cross-level interaction effect of majority contact with collective experienced discrimination by minority students at the classroom level was not significant. These contextual models provide again partial support for $\mathrm{H} 2$ on minority distancing.

\section{FIGURE 4 ABOUT HERE}

Models with collective minority perceptions of unfair treatment as a contextual moderator. The interaction of majority contact with collective perceptions of unfair treatment by minority students at the classroom level was significant on attitudes towards the minority group, thus replicating our findings with individual perceptions of unfair treatment (see Table 
3 and Figure 5). Examining the interaction further, more majority contact predicted significantly less positive attitudes towards the minority group in classrooms where minority students collectively perceived more unfair treatment $(p=.004)$; when minority students collectively perceived schools as more equal, majority contact was again unrelated to minority attitudes $(p>.374)$. For minority identification, the interaction of majority contact with collective perceptions of unfair treatment was not significant. We conclude that the additional support for $\mathrm{H} 2$ on minority group distancing with contextual measures of unfair treatment is restricted to the evaluative component of minority belonging.

\section{FIGURE 5 ABOUT HERE}

\section{Supplementary analyses of minority group distancing}

To exclude that our finding of minority group distancing with more majority contact is due to less contact with minority peers as a competing explanation, we replicated the analyses for $\mathrm{H} 2$ while controlling for a separate measure of positive contact with minority group members. The results were robust so that we found a significant and meaningful interaction effect of majority contact with discrimination experiences and perceived unfair treatment on attitudes towards the minority group and a similar trend- significant interaction effect on minority identification. In addition, we replicated the analysis including all outcome measures of minority and majority belonging simultaneously in the same models. We also examined reverse causation for our main analysis with interactions, and tested whether the interactions of minority belonging (minority attitudes and strength of identification) with individual discrimination experiences and perceived unfair treatment on majority contact were significant. Only one interaction out of four was significant in the reverse causation models, thus this additional analysis supports our main conclusion relating majority contact to less minority belonging at higher levels of unequal treatment. There is also some support for a reversed causal path, so that in one set of models higher identifiers would engage less in 
positive majority contact when they experienced more unequal treatment (qualifying a significantly negative main effect of minority identification on majority contact). Finally, we replicated the main analyses to test $\mathrm{H} 2$ on minority group distancing using a more narrow and explicit measure of discrimination experiences specifically on ethnic or religious grounds. Interested readers can find all additional analyses in Supplemental Materials.

\section{Discussion}

“Today, I tell people straight away and with a big smile on my face I'm half Belgian and half Moroccan and like to refer to myself as the product of multicultural society" says the same Moroccan Belgian woman who described her earlier experiences of unequal treatment as a teenager at the beginning of this paper. Like she does, many second and third generation immigrants sustain belonging to both the national majority and the immigrant-origin minority group (Berry, 2001; Nguyen \& Benet-Martínez, 2013). However, many also feel that such feelings of belonging to both the majority and minority group are being questioned (Azzi, 2010; Chryssochoou \& Lyons, 2010). Immigrant-origin youth often have positive interpersonal relationships with majority members but also at the same time experience unequal treatment ([BLINDED]; Tropp, 2007). We expected that such mixed experiences would impact their feelings of belonging both to the majority group and to their minority group. Recent studies showed that when minority members have positive contact with the majority group, they can experience enhanced belonging to the majority group but also distance themselves from the minority group (Derks et al., 2016; Hässler et al., 2020; Maliepaard \& Phalet, 2012; Wright \& Lubensky, 2013). In parallel, when members of immigrant-origin minority groups navigate environments that are characterized by unequal treatment, there can be a trade-off between their belonging to either the majority group or the minority group (Fleischmann \& Phalet, 2016; Wiley \& Deaux, 2010). The current study engaged with these questions and examined the effect of positive contact with the majority 
and unequal treatment on the feelings of both majority and minority group belongings of second or later generation Turkish and Moroccan Belgian youth. To account for their positive and negative experiences with members of majority groups, we combined different strands of research on intergroup contact and unequal treatment, research topics that are often investigated in isolation. We investigated how identities may be grounded in positive contact and unequal treatment experiences with members of majority groups and focused on whether contact with the majority is related to a stronger sense of belonging to the majority but distancing from the minority only when children of immigrants experience unequal treatment.

\section{Majority group belonging: positive majority contact and unequal treatment}

Summing up, the results fully confirmed Hypothesis 1a on intergroup contact and majority group belonging, in line with the acceptance of minority youth as fellow majority group members in positive intergroup interactions. Specifically, we established that friendship with native majority peers predicted more positive majority group attitudes and stronger identification. We replicated previous results associating majority friendship with majority belonging in minority youth (Leszczensky et al., 2016; Munniksma et al., 2015). In line with Hypothesis $1 \mathrm{~b}$ on unequal treatment and majority belonging, the results further showed that discrimination experiences and perceived unfair treatment predicted less positive majority group attitudes and weaker identification. These findings replicate existing evidence associating unequal treatment with less belonging to the majority group for minority persons (Hutchison et al., 2015; Jasinskaja-Lahti et al., 2009).

\section{Minority group distancing: the interplay of positive contact and unequal treatment}

Secondly, the results partially confirmed the second hypothesis on minority group distancing in the face of identity threat. We found that positive contact with the majority was only related to less positive attitudes towards the minority group (though unrelated to minority identification as such) when contact co-occurred unequal treatment. These results replicate 
across individually and collectively experienced discrimination and perceived unfair treatment as distinct measures of unequal treatment, as well as with a more narrow measure of unequal treatment on ethnic or religious grounds specifically, providing strong support for the role of inequality in the intergroup context. These results resonate with recent findings suggesting that when minority group members have more positive contact with majority group members, they tend to distance themselves from the minority group (Dixon et al., 2012; Hässler et al., 2020; Maliepaard \& Phalet, 2012; Wright \& Lubensky, 2013). This strand of critical contact research has yielded mixed findings, however, begging the question why distancing is found in some intergroup settings and not in others (Hässler et al., 2020). To our knowledge, no previous research has directly tested the role of unequal treatment in the intergroup context along with positive majority contact in minority samples. Our school-based study highlights the institutional context of intergroup relations in supporting the belonging of minority group members through enabling them to engage in positive majority contact while protecting them from unequal treatment. Keeping up good relations with the majority group may only come at the price of minority group distancing when minority youth individually or collectively experience unequal treatment in schools. The findings imply that minority group distancing is not inherent in minority-majority relations in the presence of equal treatment in the local institutional context. Indeed, intergroup contact does not preclude identification with the minority group in the absence of differential treatment. For instance, when majority group members acknowledged inequality, collective action by minority members was not undermined by intergroup contact (Becker et al., 2013; Hässler et al., 2020). Furthermore, these results highlight the importance of equality at different levels: even though the societal relations between immigrant-origin minorities and native majorities in Belgium may be unequal, equal treatment as experienced in mixed classrooms as local intergroup contexts can 
effectively buffer minority group belonging (Hodson, Hewstone, \& Swart, 2012; Phalet \& Swyngedouw, 2003 [BLINDED]).

To examine how minority intergroup experiences inform their belonging, we distinguished between affective and evaluative components of group identities: strength of identification with - and attitudes towards both minority and majority groups (Ashmore et al., 2004). Our failure to replicate minority group distancing with strength of identification is in line with earlier research on gender and self-distancing, which was mainly about the devaluation of minority group identities and less about the strength of group identities (Derks et al., 2016, 2015; Plaut, Thomas, \& Goren, 2009). Plausibly, minority group distancing was restricted to the evaluative component of the minority identities in our study, because the chronic salience of Turkish and Moroccan ethnic and religious identities in European societies may preclude dissociation from the devalued minority group as a viable identity strategies (Fleischmann \& Phalet, 2016).

We extended previous research by examining the associations of friendship with majorities with both majority and minority belonging, thus complementing a predominant focus on either majority or minority group identities in intergroup contact and stigma research respectively. Yet, both groups are meaningful parts of immigrant-origin minorities' worlds and selves and belonging to both majority and minority groups has been shown to benefit both individual immigrants and society at large. Therefore, understanding how majority contact relates to and both majority and minority group belonging is crucial to better understand minority experiences of intergroup contact in today's multicultural societies (Azzi, 2010; Berry, 2001; Nguyen \& Benet-Martínez, 2013).

\section{Individual and collective minority experiences of unequal treatment}

We used measures of both perceptions of discrimination and unequal treatment to capture inequality and the resulting identity threat in schools. We find that minority 
experiences of discrimination and unfair treatment predict less belonging to both the majority and minority group. Though the results were similar for both measures of unequal treatment, general perceptions of unfair treatment were even stronger negative predictors of both minority and majority belonging than personal experiences of discrimination. Possibly, perceived unequal treatment in schools as key institutions regulating intergroup relations send an even stronger message that the minority identity is devalued than incidental personal experiences of discrimination. Conversely, when schools are seen to institutionally sanction equal treatment of all students, they send a strong message to minority group members in particular that their minority groups are accepted and valued in school. In support of this interpretation, we largely replicated our main findings with contextual measures of collective minority experiences of unequal treatment at the classroom level. Indeed, collective experiences of discrimination and unfair treatment by minority students showed the same interplay with positive majority contact that we also found at the individual level. Apparently, collective minority experiences of unequal treatment can elicit identity threat even in the absence of negative individual experiences. These results resonate with existing evidence that collective discrimination experiences matter over and above individual experiences (Bourguignon, Seron, Yzerbyt, \& Herman, 2006; Smith, Pettigrew, Pippin, \& Bialosiewicz, 2011). To conclude, in order to protect minority identities it is imperative that schools strive to ensure equal treatment for all their students.

\section{Limitations and future directions}

This study also has limitations. The results are based on cross-sectional data and we cannot unambiguously decide on the causal direction. The current analysis largely supports our main hypothesis that majority contact is related to minority distancing at higher levels of unequal treatment. While majority contact may thus entail minority group distancing in the presence of inequality, there is some evidence of a reverse causal path as well: higher 
minority identifiers also engage less in majority contact - especially when they perceive more unequal treatment. Together these findings suggest bidirectional associations between majority contact and minority belonging. Mainly for theoretical and applied reasons, however, we focused on minority belonging as a critical outcome of the intergroup experiences of minority youth in schools. While minority belonging has been extensively documented as a key outcome in developmental research with minority youth, it has hitherto remained underresearched in the (critical) intergroup contact literature (Hughes, Watford, \& Del Toro, 2016; Umaña-Taylor et al., 2014; Verkuyten \& Fleischmann, 2017). A distinctive strength of this study is that we replicate similar patterns relating minority group distancing to unequal intergroup contact across several measures, both at the individual and at the contextual level. Especially more external contextual measures of unequal treatment suggest that perceived unequal treatment is not only a consequence of failed belonging on the side of minority youth. Future research should replicate our main findings with more rigorous longitudinal and experimental designs across a wider range of minority groups and societal intergroup contexts (CILS4EU, 2016). On a final note, our participants were minority adolescents, since adolescence is a formative period for identity development (Hughes et al., 2016; UmañaTaylor et al., 2014). Although there were no significant age differences left in the final models, bivariate correlations suggest that older minority adolescents experienced less positive majority contact along with more unequal treatment. Future studies may further explore more or less adaptive developmental trajectories of contact quality in relation to the identity development of minority youth.

\section{Implications}

Overall, the results suggest that an environment where individuals are treated equally is beneficial for harmonious intergroup relations in organizations and societies in several ways. Firstly, low unequal treatment at the personal, group or institutional level is related to 
sustained belonging to both the majority and minority group, with both groups providing unique and additive psychological and social benefits to minority persons and to society at large. Secondly, lower inequality allows minority members to reap the benefits of majority friendships without devaluing their minority group. In reverse, when organizations fail to treat members of different groups equally, for minority members maintaining positive relationships with members of majority groups may entail minority-group distancing as a way to protect their self-worth. This implication resonates with recent research relating unequal treatment to conflict or lack of compatibility between minority and majority identities for devalued minority group members. This research similarly finds that identity conflict or compatibility is contingent on the intergroup experiences of minority group members, so that minority and majority belonging are compatible in the absence of inequality (Fleischmann \& Phalet, 2016; Kende, Baysu, Fleischmann, \& Phalet, n.d.). The upshot of this is that the benefits of both majority and minority belonging can be achieved when multicultural organizations create inclusive environments where equal treatment is the norm, and where intergroup contact enables the expression and valuation of multiple minority as well as majority identities. 
MINORITY CONTACT AND INEQUALITY

\section{References}

Alba, R., \& Holdaway, J. (2013). The Integration Imperative: Introduction. In The Children of Immigrants at School: A Comparative Look at Integration in the United States and Western Europe, edited by R. Alba, and J. Holdaway (pp. 1-38).

Ashmore, R. D., Deaux, K., \& McLaughlin-Volpe, T. (2004). An Organizing Framework for Collective Identity: Articulation and Significance of Multidimensionality. Psychological Bulletin, Vol. 130, pp. 80-114. https://doi.org/10.1037/0033-2909.130.1.80

Azzi, A. E. (2010). Conclusion: From Identity and Participation to Integration or Radicalization. In Identity and Participation in Culturally Diverse Societies (pp. 359367). https://doi.org/10.1002/9781444328158.oth1

Baysu, G., Phalet, K., \& Brown, R. (2011). Dual identity as a two-edged sword: Identity threat and minority school performance. Social Psychology Quarterly, 74(2), 121-143. https://doi.org/10.1177/0190272511407619

Baysu, G., Phalet, K., \& Brown, R. (2014). Relative group size and minority school success: The role of intergroup friendship and discrimination experiences. British Journal of Social Psychology, 53(2), 328-349. https://doi.org/10.1111/bjso.12035

Becker, J. C., Wright, S. C., Lubensky, M. E., \& Zhou, S. (2013). Friend or ally: Whether cross-group contact undermines collective action depends on what advantaged group members say (or don't say). Personality and Social Psychology Bulletin, 39(4), 442-455. https://doi.org/10.1177/0146167213477155

Berry, J. W. (2001). A Psychology of Immigration. Journal of Social Issues, 57(3), 615-631.

Bourguignon, D., Seron, E., Yzerbyt, V., \& Herman, G. (2006). Perceived group and personal discrimination: Differential effects on personal self-esteem. European Journal of Social Psychology, 36(5), 773-789. https://doi.org/10.1002/ejsp.326 
Branscombe, N. R., Ellemers, N., Spears, R., \& Doosje, B. (1999). The context and content of social identity threat. In N. Ellemers, R. Spears, \& B. Doosje (Eds.), Social identity: Context, commitment, content (pp. 35-58). Oxford, UK: Blackwell Science.

Branscombe, N. R., Fernandez, S., Gomez, A., \& Cronin, T. (2012). Moving toward or away from a group identity: Different strategies for coping with pervasive discrimination. In J. Jetten, C. Haslam, \& S. A. Haslam (Eds.), The Social Cure: Identity, Health and WellBeing (pp. 115-132). https://doi.org/10.4324/9780203813195

Cakal, H., Hewstone, M., Schwär, G., \& Heath, A. (2011). An investigation of the social identity model of collective action and the "sedative" effect of intergroup contact among Black and White students in South Africa. British Journal of Social Psychology, 50(4), 606-627. https://doi.org/10.1111/j.2044-8309.2011.02075.x

Chryssochoou, X., \& Lyons, E. (2010). Perceptions of (In)Compatibility between Identities and Participation in the National Polity of People belonging to Ethnic Minorities. In Identity and Participation in Culturally Diverse Societies (pp. 69-88). https://doi.org/10.1002/9781444328158.ch4

CILS4EU. (2016). Children of Immigrants Longitudinal Survey in Four European Countries: Codebook. Wave 1 -2010/2011, v1.1.0. Mannheim, Germany: Mannheim University.

Davies, K., Tropp, L. R., Aron, A., Pettigrew, T. F., \& Wright, S. C. (2011). Cross-group friendships and intergroup attitudes: A meta-analytic review. Personality and Social Psychology Review, 15(4), 332-351. https://doi.org/10.1177/1088868311411103

Deaux, K., \& Verkuyten, M. (2014). The Social Psychology of MulticulturalismIdentity and Intergroup Relations. In V. Benet-Martínez \& Y. Hong (Eds.), The Oxford Handbook of Multicultural Identity (pp. 118-138).

https://doi.org/10.1093/oxfordhb/9780199796694.013.015

Derks, B., Van Laar, C., \& Ellemers, N. (2016). The queen bee phenomenon: Why women 
leaders distance themselves from junior women. Leadership Quarterly, 27(3), 456-469. https://doi.org/10.1016/j.leaqua.2015.12.007

Derks, B., van Laar, C., Ellemers, N., \& Raghoe, G. (2015). Extending the Queen Bee Effect: How Hindustani Workers Cope with Disadvantage by Distancing the Self from the Group. Journal of Social Issues, 71(3), 476-496. https://doi.org/10.1111/josi.12124

Dixon, J., Levine, M., Reicher, S., \& Durrheim, K. (2012). Beyond prejudice: Are negative evaluations the problem and is getting us to like one another more the solution? Behavioral and Brain Sciences, 35(06), 411-425. https://doi.org/10.1017/S0140525X11002214

Emonds, V., Meeus, A., Heikamp, T., \& Meuleman, B. (2015). Technical report Leuven Children of Immigrants Longitudinal Study 2012-2015. Leuven: CeSo-CSCP: University of Leuven.

Fleischmann, F., \& Phalet, K. (2016). Identity Conflict or Compatibility: A Comparison of Muslim Minorities in Five European Cities. Political Psychology, 37(4), 447-463. https://doi.org/10.1111/pops.12278

Fleischmann, F., Phalet, K., \& Klein, O. (2011). Religious identification and politicization in the face of discrimination: Support for political Islam and political action among the Turkish and Moroccan second generation in Europe. British Journal of Social Psychology, 50(4), 628-648. https://doi.org/10.1111/j.2044-8309.2011.02072.x

Hässler, T., Ullrich, J., Bernardino, M., Shnabel, N., Laar, C. Van, Valdenegro, D., ... Ugarte, L. M. (2020). A large-scale test of the link between intergroup contact and support for social change. Nature Human Behaviour. https://doi.org/10.1038/s41562-019-0815-z

Hodson, G., Hewstone, M., \& Swart, H. (2012). Epilogue and future directions. In G. Hodson \& M. Hewstone (Eds.), Advances in intergroup contact (pp. 262-304). New York: Psychology Press. 
Hox, J. J., Moerbeek, M., \& van de Schoot, R. (2010). Multilevel analysis: Techniques and applications. New York, NY: Routledge.

Hughes, D. L., Watford, J. A., \& Del Toro, J. (2016). A Transactional/Ecological Perspective on Ethnic-Racial Identity, Socialization, and Discrimination. In Advances in Child Development and Behavior (Vol. 51, pp. 1-41). https://doi.org/10.1016/bs.acdb.2016.05.001

Hughes, J. N., \& Chen, Q. (2011). Reciprocal effects of student-teacher and student-peer relatedness: Effects on academic self efficacy. Journal of Applied Developmental Psychology, 32(5), 278-287. https://doi.org/https://doi.org/10.1016/j.appdev.2010.03.005

Hutchison, P., Lubna, S. A., Goncalves-Portelinha, I., Kamali, P., \& Khan, N. (2015). Groupbased discrimination, national identification, and British Muslims' attitudes toward nonMuslims: The mediating role of perceived identity incompatibility. Journal of Applied Social Psychology, 45(6), 330-344. https://doi.org/10.1111/jasp.12299

Iyer, A., \& Ryan, M. K. (2009). Why Do Men and Women Challenge Gender Discrimination in the Workplace? The Role of Group Status and In-group Identification in Predicting Pathways to Collective Action. Journal of Social Issues, 65(4), 791-814. https://doi.org/10.1111/j.1540-4560.2009.01625.x

Jasinskaja-Lahti, I., Liebkind, K., \& Solheim, E. (2009). To identify or not to identify? National disidentification as an alternative reaction to perceived ethnic discrimination. Applied Psychology, 58(1), 105-128. https://doi.org/10.1111/j.1464-0597.2008.00384.x

Kamberi, E., Martinovic, B., \& Verkuyten, M. (2017). Intergroup contact and minority group empowerment: The perspective of Roma and non-Roma adolescents in Macedonia. Journal of Community and Applied Social Psychology, 27(5), 424-434. https://doi.org/10.1002/casp.2320 
Kanas, A., van Tubergen, F., \& van der Lippe, T. (2011). The role of social contacts in the employment status of immigrants: A panel study of immigrants in Germany. International Sociology, 26(1), 95-122. https://doi.org/10.1177/0268580910380977

Kende, J., Baysu, G., Fleischmann, F., \& Phalet, K. (n.d.). Dual identities in context: the role of minority peers and school discrimination in the socialization of national and ethnic identification. In Preparation.

Kende, J., Phalet, K., Van den Noortgate, W., Kara, A., \& Fischer, R. (2018). Equality Revisited: A Cultural Meta-Analysis of Intergroup Contact and Prejudice. Social Psychological and Personality Science, 9(8), 887-895. https://doi.org/10.1177/1948550617728993

Klein, O., Spears, R., \& Reicher, S. (2007). Social identity performance: Extending the strategic side of SIDE. Personality and Social Psychology Review, 11(1), 28-45. https://doi.org/10.1177/1088868306294588

Leszczensky, L., Stark, T. H., Flache, A., \& Munniksma, A. (2016). Disentangling the relation between young immigrants' host country identification and their friendships with natives. Social Networks, 44, 179-189. https://doi.org/10.1016/j.socnet.2015.08.001

Mähönen, T. A., \& Jasinskaja-Lahti, I. (2016). Ramifications of positive and negative contact experiences among remigrants from Russia to Finland. Cultural Diversity and Ethnic Minority Psychology, 22(2), 247-255. https://doi.org/10.1037/cdp0000059

Major, B., \& O’Brien, L. T. (2005). The Social Psychology of Stigma. Annual Review of Psychology, 56(1), 393-421. https://doi.org/10.1146/annurev.psych.56.091103.070137

Maliepaard, M., \& Phalet, K. (2012). Social integration and religious identity expression among Dutch Muslims: The role of minority and majority group contact. Social Psychology Quarterly, 75(2), 131-148. https://doi.org/10.1177/0190272511436353

Munniksma, A., Verkuyten, M., Flache, A., Stark, T. H., \& Veenstra, R. (2015). Friendships 
and outgroup attitudes among ethnic minority youth: The mediating role of ethnic and host society identification. International Journal of Intercultural Relations, 44, 88-99. https://doi.org/10.1016/j.ijintrel.2014.12.002

Nguyen, A. M. T. D., \& Benet-Martínez, V. (2013). Biculturalism and Adjustment: A MetaAnalysis. Journal of Cross-Cultural Psychology, 44(1), 122-159. https://doi.org/10.1177/0022022111435097

Noguera, P. A. (2004). Social capital and the education of immigrant students: Categories and generalizations. Sociology of Education, 77(2), 180-183. https://doi.org/10.1177/003804070407700206

Phalet, K., Fleischmann, F., \& Swyngedouw, M. (2018). Religious identities and civic integration. In Growing Up Muslim in Europe and the United States (pp. 57-73). https://doi.org/10.4324/9781315279091-4

Phalet, K., \& Swyngedouw, M. (2003). Measuring immigrant integration: The case of Belgium. Studi Emigrazione, 40(152), 773-804.

Plaut, V. C., Thomas, K. M., \& Goren, M. J. (2009). Is multiculturalism or color blindness better for minorities? Psychological Science, 20(4), 444-446. https://doi.org/10.1111/J.1467-9280.2009.02318.X

Reimer, N. K., Becker, J. C., Benz, A., Christ, O., Dhont, K., Klocke, U., ... Hewstone, M. (2016). Intergroup Contact and Social Change. Personality and Social Psychology Bulletin, 43(1), 121-136. https://doi.org/10.1177/0146167216676478

Reimer, N. K., Schmid, K., Love, A., \& Hewstone, M. (2019). Can inter-group contact foster solidarity across social divides? Presentation at the Annual Meetingof the International Society of Political Psychology, Lisbon, Portugal.

Roblain, A., Azzi, A., \& Licata, L. (2016). Why do majority members prefer immigrants who adopt the host culture? The role of perceived identification with the host nation. 
MINORITY CONTACT AND INEQUALITY

International Journal of Intercultural Relations, 55, 44-54.

https://doi.org/10.1016/j.ijintrel.2016.08.001

Smith, H. J., Pettigrew, T. F., Pippin, G. M., \& Bialosiewicz, S. (2011). Relative Deprivation. Personality and Social Psychology Review, 16(3), 203-232. https://doi.org/10.1177/1088868311430825

Stand Against Racism. (2015). Everyday racism in Belgium. Retrieved January 7, 2019, from https://www.facebook.com/permalink.php?story_fbid=415836158577919\&id=40674261 9487273

Tabachnick, B. G., \& Fidell, L. S. (2013). Using multivariate statistics (6th ed.). New York: Pearson.

Thijs, J., Hornstra, L., \& Charki, F. Z. (2018). Self-Esteem and National Identification in Times of Islamophobia: A Study Among Islamic School Children in The Netherlands. Journal of Youth and Adolescence, 47(12), 2521-2534. https://doi.org/10.1007/s10964018-0906-6

Thomsen, J. P. F., \& Rafiqi, A. (2016). The contact-prejudice relationship among ethnic minorities: examining personal discrimination as a boundary condition. Ethnic and Racial Studies, 39(10), 1886-1904. https://doi.org/10.1080/01419870.2015.1110609

Tropp, L. R. (2006). Stigma and intergroup contact among members of minority and majority status groups. In S. Levin \& C. Van Laar (Eds.), Stigma and group inequality: Social psychological perspectives (pp. 171-191). Mahwah, NJ: Lawrence Erlbaum.

Tropp, L. R. (2007). Perceived Discrimination and Interracial Contact: Predicting Interracial Closeness among Black and White Americans. Social Psychology Quarterly, 70(1), 7081. https://doi.org/10.1177/019027250707000108

Umaña-Taylor, A. J., Quintana, S. M., Lee, R. M., Cross, W. E., Rivas-Drake, D., Schwartz, S. J., ... Sellers, R. M. (2014). Ethnic and Racial Identity During Adolescence and Into 
Young Adulthood: An Integrated Conceptualization. Child Development, 85(1), 21-39. https://doi.org/10.1111/cdev.12196

Van Laar, C., Bleeker, D., Ellemers, N., \& Meijer, E. (2014). Ingroup and outgroup support for upward mobility: Divergent responses to ingroup identification in low status groups. European Journal of Social Psychology, 44(6), 563-577. https://doi.org/10.1002/ejsp.2046

Verkuyten, M., \& Fleischmann, F. (2017). Ethnic Identity among Immigrant and Minority Youth. In A. Rutland, D. Nesdale, \& C. S. Brown (Eds.), The Wiley Handbook of Group Processes in Children and Adolescents (pp. 23-46). https://doi.org/10.1002/9781118773123.ch2

Wiley, S., \& Deaux, K. (2010). The Bicultural Identity Performance of Immigrants. In A. E. Azzi, X. Chryssochoou, B. Klandermans, \& B. Simon (Eds.), Identity and Participation in Culturally Diverse Societies (pp. 49-68). https://doi.org/10.1002/9781444328158.ch3

Wright, S. C., \& Lubensky, M. E. (2013). The struggle for social equality: Collective action versus prejudice reduction. In S. Demoulin, J.-P. Leyens, \& J. F. Dovidio (Eds.), Intergroup Misunderstandings Impact of Divergent Social Realities (pp. 291-310). https://doi.org/10.4324/9780203848814 
Table 1. Correlations among control, predictor and outcome variables.

\begin{tabular}{|c|c|c|c|c|c|c|c|c|c|c|}
\hline & 1 & 2 & 3 & 4 & 5 & 6 & 7 & 8 & 9 & 10 \\
\hline 1. Age (1) & 1.00 & & & & & & & & & \\
\hline 2. Gender (2) & .02 & 1 & & & & & & & & \\
\hline 3. Positive majority contact ( 3 ) & $-.09^{* *}$ & -.01 & 1 & & & & & & & \\
\hline 4. Experiences of discrimination (4) & .02 & $-.07^{*}$ & .05 & 1 & & & & & & \\
\hline 5. Perceptions of unfair treatment (5) & $.08^{* *}$ & -.02 & .00 & $.17^{* *}$ & 1 & & & & & \\
\hline 6. Attitude towards majority (6) & .00 & $.09^{* *}$ & $.34^{* *}$ & $-.14^{* *}$ & $-.11^{* *}$ & 1 & & & & \\
\hline 7. Majority identification (7) & -.02 & $.12^{* *}$ & $.32^{* *}$ & .01 & $-.09^{* *}$ & $.28^{* *}$ & 1 & & & \\
\hline 8. Attitude towards minority (8) & -.01 & .02 & $-.11^{* *}$ & $-.17^{* *}$ & $-.09^{* *}$ & $.12^{* *}$ & $-.15^{* *}$ & 1 & & \\
\hline 9. Minority identification (9) & .03 & .01 & $-.13 * *$ & .02 & -.03 & $-.08 *$ & $-0.1 * *$ & $.17^{* *}$ & 1 & \\
\hline 10. Class composition (10) & $.08^{* *}$ & .01 & $-.26^{* *}$ & $-.09^{* *}$ & $-.08^{* *}$ & $-.10^{* *}$ & -.04 & $.09^{* *}$ & .03 & 1 \\
\hline
\end{tabular}


Table 2. Relationship of positive majority contact and individual perceptions of unfair treatment as predictors of majority and minority attitude and identification as outcomes.

\begin{tabular}{|c|c|c|c|c|}
\hline & $\begin{array}{l}\text { Attitudes towards } \\
\text { majority }\end{array}$ & $\begin{array}{l}\text { Majority } \\
\text { identification }\end{array}$ & $\begin{array}{l}\text { Attitudes towards } \\
\text { minority }\end{array}$ & $\begin{array}{l}\text { Minority } \\
\text { identification }\end{array}$ \\
\hline & B (S.E.) & B (S.E.) & B (S.E.) & B (S.E.) \\
\hline \multicolumn{5}{|l|}{ INDIVIDUAL LEVEL } \\
\hline Positive Majority Contact (CO) & $6.66(0.62)^{* * *}$ & $0.36(0.03)^{* * *}$ & $-1.40(0.52)^{* *}$ & $-0.12(0.04)^{* * *}$ \\
\hline Perceptions of unfair treatment (FA) & $-2.73(0.71) * * *$ & $-0.11(0.04)^{*}$ & $-1.57(0.6)^{* *}$ & $-0.03(0.04)$ \\
\hline $\mathrm{CO} * \mathrm{FA}$ & $-0.08(0.65)$ & $-0.01(0.03)$ & $-0.99(0.49)^{*}$ & $-0.06(0.03)^{*}$ \\
\hline \multicolumn{5}{|l|}{ Control variables } \\
\hline Age & $0.86(0.58)$ & $0.02(0.03)$ & $-0.46(0.58)$ & $-0.01(0.04)$ \\
\hline Gender & $3.99(1.45)^{* *}$ & $0.32(0.08)^{* * *}$ & $0.45(1.14)$ & $0.05(0.08)$ \\
\hline \multicolumn{5}{|l|}{ CLASS LEVEL } \\
\hline Composition & $-1.94(3.37)$ & $0.22(0.18)$ & $4.40(1.70) \dagger$ & $-0.09(0.20)$ \\
\hline \multicolumn{5}{|l|}{ MODEL FIT } \\
\hline Deviance (-2LL) & 9024.36 & 3666.84 & 8525.80 & 3732.64 \\
\hline Akaike (AIC) & 9042.36 & 3684.84 & 8543.80 & 3750.64 \\
\hline Bayesian (BIC) & 9086.50 & 3730.04 & 8587.77 & 3796.04 \\
\hline Sample-Size Adjusted BIC & 9057.92 & 3701.46 & 8559.19 & 3767.45 \\
\hline
\end{tabular}

Note: Entries represent unstandardized coefficients (SE). $* p<.05$, ** $p<.01$ (2-tailed). Gender: $0=$ male, $1=$ female 
Table 3. Relationship of positive majority contact and collective experiences of discrimination and perceptions of unfair treatment as predictors and minority attitude and strength of identification as outcomes.

\begin{tabular}{|c|c|c|c|c|}
\hline & $\begin{array}{l}\text { Attitudes towards } \\
\text { minority }\end{array}$ & $\begin{array}{l}\text { Minority } \\
\text { identification }\end{array}$ & $\begin{array}{l}\text { Attitudes towards } \\
\text { minority }\end{array}$ & $\begin{array}{l}\text { Minority } \\
\text { identification }\end{array}$ \\
\hline & B (S.E.) & B (S.E.) & B (S.E.) & B (S.E.) \\
\hline \multicolumn{5}{|l|}{ INDIVIDUAL LEVEL } \\
\hline Positive Majority Contact (CO) & $-1.55(0.52)^{* *}$ & $-0.09(0.02)^{* * *}$ & $-1.50(0.54)^{* *}$ & $-0.13(0.04)^{* * *}$ \\
\hline Experiences of discrimination & $-3.63(1.56)^{*}$ & $-0.08(0.06)$ & & \\
\hline Perceptions of unfair treatment & & & $-1.62(0.71)^{*}$ & $-0.02(0.04)$ \\
\hline \multicolumn{5}{|l|}{ Control variables } \\
\hline Age & $-0.69(0.58)$ & $0.02(0.03)$ & $-0.49(0.58)$ & $-0.01(0.04)$ \\
\hline Gender & $0.09(1.17)$ & $-0.13(0.06)^{*}$ & $0.52(1.15)$ & $0.05(0.08)$ \\
\hline \multicolumn{5}{|l|}{ CLASS LEVEL } \\
\hline Composition & $3.34(2.46)$ & $-0.13(0.12)$ & $4.72(2.57)^{\dagger}$ & $-0.11(0.21)$ \\
\hline $\begin{array}{l}\text { Collective experiences of discrimination } \\
\text { (DI) }\end{array}$ & $-1.04(2.09)$ & $0.04(0.11)$ & & \\
\hline \multicolumn{5}{|c|}{ Collective perceptions of unfair treatment } \\
\hline CO*DI & $-3.30(1.68)^{*}$ & $0.08(0.05)$ & & \\
\hline $\mathrm{CO} * \mathrm{FA}$ & & & $-1.36(0.78) \dagger$ & $-0.06(0.05)$ \\
\hline \multicolumn{5}{|l|}{ MODEL FIT } \\
\hline Deviance (-2LL) & 8239.48 & 3719.84 & 8486.98 & 3719.84 \\
\hline Akaike (AIC) & 8261.481 & 3741.84 & 8508.99 & 3741.84 \\
\hline Bayesian (BIC) & 8314.89 & 3797.285 & 8562.67 & 3797.29 \\
\hline Sample-Size Adjusted BIC & 8279.955 & 3762.346 & 8527.73 & 3762.35 \\
\hline
\end{tabular}


Figure 1. Attitudes towards the minority group at low (-1 SD) and high (+1 SD) individual perceptions of unfair treatment and low (-1 SD) and high (+1 SD) majority contact

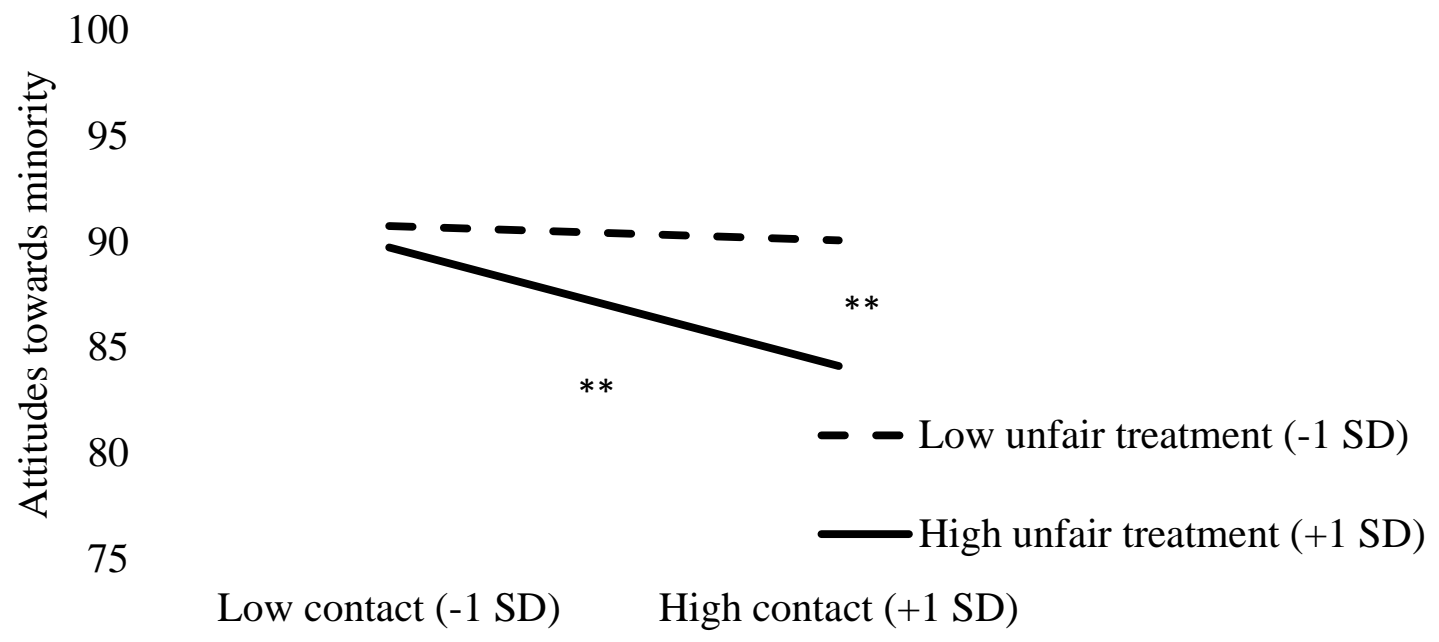

Figure 2. Minority identification at low (-1 SD) and high (+1 SD) perceptions of unfair treatment and low (-1 SD) and high (+1 SD) majority contact

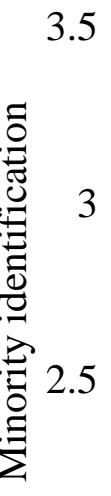

2

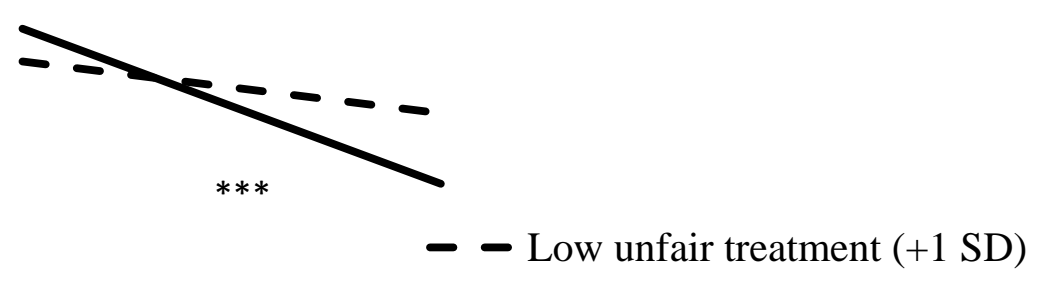

High unfair treatment (-1 SD)

Low contact (-1 SD) High contact (+1 SD) 
Figure 3. Attitudes towards the minority group at low (-1 SD) and high (+1 SD) individual experiences of discrimination and low (-1 SD) and high (+1 SD) majority contact

100
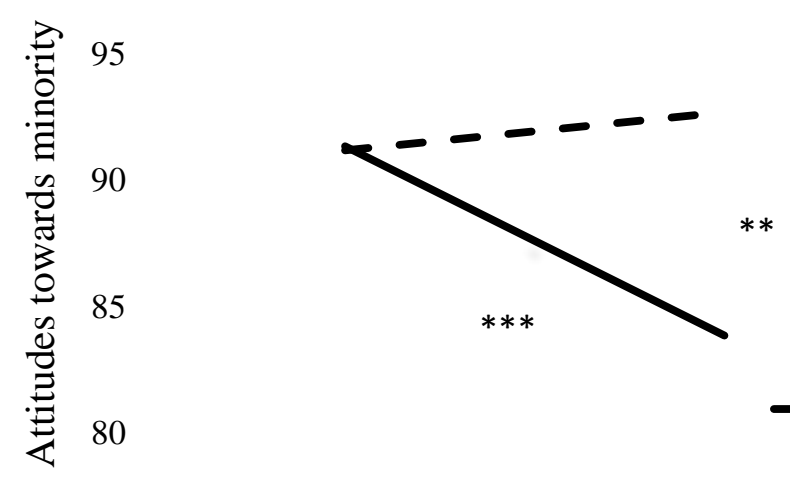

- - Low discrimination (-1 SD)

- High discrimination (+1 SD)

75

Low contact (-1 SD) High contact (+1 SD)

Figure 4. Attitudes towards the minority group at low (-1 SD) and high (+1 SD) collective experiences of discrimination and low (-1 SD) and high (+1 SD) majority contact

100
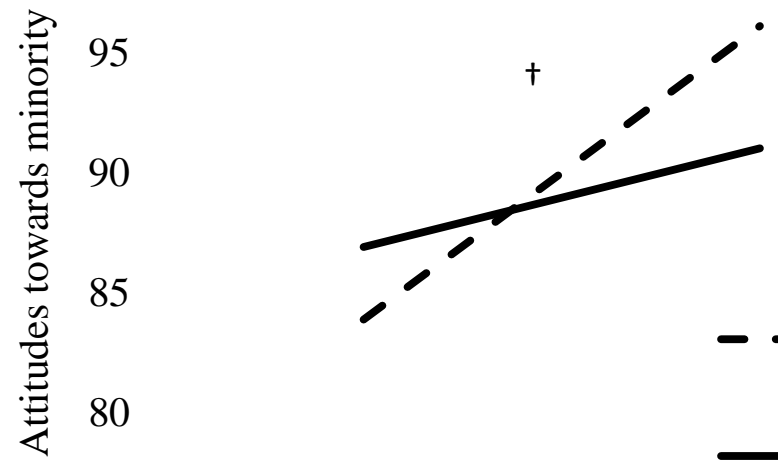

- - Low collective discrimination (-1 SD)

High collective discrimination (+1SD)

75

Low contact (-1 SD) High contact (+1 SD) 
Figure 5. Attitudes towards the minority group at low (-1 SD) and high (+1 SD) collective perceptions of unfair treatment and low (-1 SD) and high (+1 SD) majority contact

100

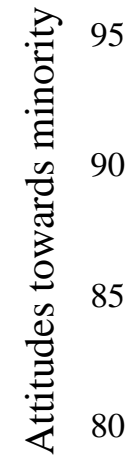

75

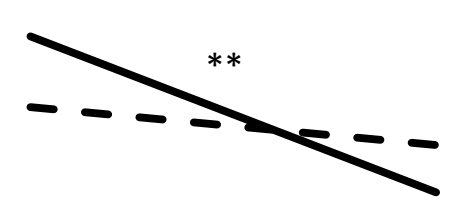

- - Low collective unfair treatment (-1 SD)

- High collective unfair treatment (+1 SD)

Low contact (-1 SD) High contact (+1 SD) 


\section{Online Supplementary Materials}

\section{Partitioning of variance in outcome variables}

The variance at the class level was higher for all of the outcome variables than the variance at the school level. More specifically, for attitude towards the majority group the variance at the class level was $3.2 \%$ and at the school level $2.9 \%$, for strength of majority identification $7.7 \%$ at the class level and $2.5 \%$ at the school level, for attitude towards the minority group $4.5 \%$ at the class level and $2.7 \%$ at the school level and for strength of minority identification $11 \%$ at the class level and $7 \%$ at the school level.

\section{Consecutive steps for testing the Hypotheses and corresponding model fit}

\section{information}

To test Hypotheses 1, two sets of multilevel regression analyses were run for both majority-related measures of belonging. Both sets of analyses tested the expected associations of positive majority contact (H1a) and of unequal treatment (in separate sets of models for experiences of discrimination and unfair treatment) (H1b) as predictors, with attitudes towards the majority and with strength of majority identification as dependent measures. The analyses were run in consecutive steps (Hox, Moerbeek, \& van de Schoot, 2010; Tabachnick \& Fidell, 2013) starting from the null model; secondly including level 1 predictors - i.e., our composite measure of positive majority contact and either experiences of discrimination or perceptions of unfair treatment while controlling for age and gender; thirdly including the level 2 control variable ethnic class-composition ("main effects" model); and finally adding the interaction between contact and either experiences of discrimination or perceptions of unfair treatment (“interaction" model).

To investigate Hypothesis 2, two sets of multilevel regression analyses were run for both minority-related measures of belonging. Both sets of analyses related positive majority contact as 
the main predictor with attitudes towards minority groups and minority identification as dependent measures, with either experiences of discrimination or perceptions of unfair treatment as hypothetical moderators. These analyses were also run in consecutive steps following the same sequence as Hypothesis 1, and finally adding the interaction between positive majority contact and either experiences of discrimination or perceptions of unfair treatment ("interaction" model).

To test Hypothesis 1 (see Table S1 in Supplemental Materials), we first tested the main effects of positive majority contact and experiences of discrimination on majority belonging (attitudes and strength of identification) (H1a). Next, we replicated the same models with perceived unfair treatment as predictor (H1b). In both sets of models, the "main effects model" with positive majority contact and experiences of discrimination or unfair treatment (as well as age, gender and ethnic composition controls) resulted in a significant improvement in model fit over the null model for both outcome measures of majority belonging (see Table S2 with fit statistics in online supplemental materials).

Likewise, to test Hypothesis 2 (see Table S2), we first tested the main effects of positive majority contact and experiences of discrimination on minority belonging (attitudes and strength of identification). Next, we replicated the same model with perceptions of unfair treatment. The "main effects model" with positive majority contact and experiences of discrimination or perceptions of unfair treatment (as well as age, gender and ethnic composition controls) resulted in significant improvements in model fit over the null model for both outcome measures of minority belonging. Furthermore, the "interaction model" further improved the model fit significantly over the "main effects model" for three out of four combinations of our measures of discrimination or unfair treatment and minority belonging (except for the interaction model with experiences of discrimination as a moderator and strength of minority identification as an outcome) (see Table S2). 


\section{Supplementary analyses on minority group distancing including minority contact}

Firstly, to test a competing explanation of minority group distancing in terms of reduced contact with minority peers when minority youth are more invested in positive majority contact, we reran the main analysis while adding a separate measure of minority contact as a control variable. In this way, we ensure that our finding of minority group distancing with more positive majority contact is not simply due to less contact with minority peers.

[Models including minority contact and experiences of discrimination] Additional analyses yield the same interaction patterns controlling for minority contact (Table S4). In partial support of Hypothesis 2, more positive majority contact predicted less positive attitudes towards the minority (though not less ethnic identification) at higher levels of discrimination, regardless of the amount of positive minority contact (Figure S1).

\section{FIGURE S1 ABOUT HERE}

[Models including minority contact and perception of unfair treatment] As expected, we replicated a significant and meaningful interaction effect on attitudes towards the minority group and a trend- significant interaction effect on ethnic identification, confirming Hypothesis 2 on minority group distancing while controlling for the amount of minority contact as a competing explanation (Table S5). More positive majority contact was related to less positive attitudes towards the minority and weaker ethnic identification only at higher levels of perceived unfair treatment (Figure S2 and Figure S3).

FIGURE S2 \& S3 ABOUT HERE

\section{Further supplementary analysis with explicit ethnic discrimination as a more}

\section{narrow measure of individually experienced unfair treatment}

Secondly, as a further test of the robustness of our finding of contingent minority group distancing, we repeated the analyses using a more restricted explicit measure of experiences of 
discrimination on ethnic or religious grounds. Specifically, we reran the interaction models with minority experiences of positive majority contact and unfair treatment, including only those responses which were explicitly and specifically attributed to ethnic or religious grounds in a follow-up question. Consistent with our findings reported above, the interaction effect on attitudes toward the minority group was significant in the same expected direction (Table S6, Figure S2). The interaction effect on our ethnic identification measure was not significant (Table S7), in line with our findings using a less restrictive measure to capture minority experiences of discrimination in schools.

\section{FIGURE S4 ABOUT HERE}

\section{Further supplementary analysis testing reverse causation models}

Thirdly, we estimated alternative interaction models with reverse causal directions. Specifically, we tested whether the interaction of minority belonging (attitudes and strength of identification measures) with individual-level experiences of discrimination or perceptions of unfair treatment on positive majority contact was significant or not. Specifically, we tested four models: 1 . The interaction between experiences of discrimination and attitudes toward the minority 2. The interaction between perceptions of unfair treatment and attitudes toward the minority, 3 . The interaction between experiences of discrimination and minority identification and 4 . The interaction between perceptions of unfair treatment and minority identification. The interaction was only significant in the last reverse model: Higher minority identifiers (i.e., those with stronger minority identification) engaged less in positive majority contact when they perceived more unfair treatment. (see Tables S7 and S8).

Furthermore, neither the reverse main effects of perceived unfair treatment nor of experiences of discrimination on positive majority contact were significant. Yet, both reverse main effects of minority identification and of attitudes negatively predicted positive majority 
contact: Stronger minority identification and more positive attitudes toward the minority group were related to lower levels of intergroup contact. The four reverse-causation models fit the data well in terms of the same measures of model fit that we also used in the main analysis. 
Table S1. Model fit statistics and explained variances for stepwise models with relationship of positive majority contact and experiences of discrimination as predictors to majority and minority attitude and identification as outcomes

\begin{tabular}{|c|c|c|c|c|}
\hline Fit statistics & Null model & Level 1 predictors & Main effects model & Interaction \\
\hline \multicolumn{5}{|c|}{ ATTITUDES TOWARDS MAJORITY } \\
\hline Deviance (-2LL) & 9170.658 & 8755.768 & 8755.376 & 8755.35 \\
\hline$\chi 2 \Delta(\mathrm{df} \Delta)$ & & $\chi 2 \Delta(4)=377.473$ & $\chi^{2 \Delta}(1)=0.372$ & $\chi 2 \Delta(1)=0.015$ \\
\hline $\mathrm{p}$ value & & $p<.001$ & $p=.542$ & $p=.901$ \\
\hline R2 individual level & & 16.2 & 15.9 & 15.9 \\
\hline $\mathrm{R} 2$ class level & & & 2.2 & 2.2 \\
\hline \multicolumn{5}{|c|}{ MAJORITY IDENTIFICATION } \\
\hline Deviance (-2LL) & 3815.766 & 3566.256 & 3564.906 & 3564.51 \\
\hline$\chi 2 \Delta(\mathrm{df} \Delta)$ & & $\begin{array}{l}\chi 2 \Delta(4)=217.917 \\
p<.001\end{array}$ & $\begin{array}{l}\chi 2 \Delta(1)=1.477 \\
p=.224\end{array}$ & $\begin{array}{l}\chi 2 \Delta(1)=0.309, \\
p=.578\end{array}$ \\
\hline $\mathrm{R} 2$ individual level & & 12.5 & 13 & 13.1 \\
\hline $\mathrm{R} 2$ class level & & & 3.1 & 3.2 \\
\hline \multicolumn{5}{|c|}{ ATTITUDES TOWARDS MINORITY } \\
\hline Deviance (-2LL) & 8551.024 & 8249.894 & 8248.504 & 8236.174 \\
\hline$\chi 2 \Delta(\mathrm{df})$ & & $\chi 2 \Delta(4)=243.18$ & $\chi^{2 \Delta(1)}=1.488$ & $\chi 2 \Delta(1)=5.265$, \\
\hline $\mathrm{p}$ value & & $p<.001$ & $p=.22$ & $p=.021$ \\
\hline R2 individual level & & 3.9 & 3.6 & 4.8 \\
\hline $\mathrm{R} 2$ class level & & & 52.2 & 79.5 \\
\hline \multicolumn{5}{|c|}{ MINORITY IDENTIFICATION } \\
\hline Deviance (-2LL) & 4870.47 & 4369.76 & 4368.744 & 4368.73 \\
\hline$\chi 2 \Delta(\mathrm{df} \Delta)$ & & $\chi 2 \Delta(4)=496.404$ & $\chi 2 \Delta(1)=0.9$ & $\chi 2 \Delta(1)=0.013$ \\
\hline $\mathrm{p}$ value & & $p<.001$ & $p=.343$ & $p=.91$ \\
\hline $\mathrm{R} 2$ individual level & & 1.6 & 1.9 & 1.7 \\
\hline $\mathrm{R} 2$ class level & & & 2.8 & 3 \\
\hline
\end{tabular}

Note. Level 1 predictors model includes age, gender, experiences of discrimination and positive majority contact; Main effects model includes class composition; Interaction model includes interaction between experiences of discrimination and positive majority contact. 
Table S2. Model fit statistics and explained variances for stepwise models with relationship of positive majority contact and perceptions of unfair treatment as predictors to majority and minority attitude and identification as outcomes

\begin{tabular}{|c|c|c|c|c|}
\hline Fit statistics & Null model & Level 1 predictors & Main effects model & Interaction \\
\hline \multicolumn{5}{|c|}{ ATTITUDES TOWARDS MAJORITY } \\
\hline Deviance (-2LL) & 9170.658 & 9024.612 & 9024.382 & 9024.36 \\
\hline$\chi 2 \Delta(\mathrm{df} \Delta)$ & & $\chi 2 \Delta(4)=144.693$ & $\chi 2 \Delta(1)=0.241$ & $\chi 2 \Delta(1)=0.016$ \\
\hline $\mathrm{p}$ value & & $p<.001$ & $p=.623$ & $p=.899$ \\
\hline $\mathrm{R} 2$ individual level & & 13.9 & 13.7 & 13.7 \\
\hline $\mathrm{R} 2$ class level & & & 1.5 & 0.01 \\
\hline \multicolumn{5}{|c|}{ MAJORITY IDENTIFICATION } \\
\hline Deviance (-2LL) & 3851.636 & 3668.346 & 3667.028 & 3666.844 \\
\hline$\chi 2 \Delta(\mathrm{df} \Delta)$ & & $\chi 2 \Delta(4)=39.845$ & $\chi 2 \Delta(1)=0.027$ & $\chi^{2 \Delta(1)}=1.743$ \\
\hline $\mathrm{p}$ value & & $p<.001$ & $p=.869$ & $p=.186$ \\
\hline $\mathrm{R} 2$ individual level & & 13.2 & 13.7 & 13.8 \\
\hline $\mathrm{R} 2$ class level & & & 2.8 & 2.8 \\
\hline \multicolumn{5}{|c|}{ ATTITUDES TOWARDS MINORITY } \\
\hline Deviance (-2LL) & 8551.024 & 8532.16 & 8530.196 & 8525.802 \\
\hline$\chi^{2 \Delta}(\mathrm{df} \Delta)$ & & $\chi^{2 \Delta(4)}=18.637$ & $\chi 2 \Delta(1)=2.186$ & $\chi 2 \Delta(1)=4.568$ \\
\hline $\mathrm{p}$ value & & $p<.001$ & $p=.139$ & $p=.032$ \\
\hline $\mathrm{R} 2$ individual level & & 2 & 1.6 & 2.1 \\
\hline R2 class level & & & 6.7 & 7.9 \\
\hline \multicolumn{5}{|c|}{ MAJORITY IDENTIFICATION } \\
\hline Deviance (-2LL) & 4919.652 & 4903.154 & 4902.538 & 4898.434 \\
\hline$\chi 2 \Delta(\mathrm{df} \Delta)$ & & $\chi 2 \Delta(4)=20.331, p<.001$ & $\chi 2 \Delta(1)=2.255, p=.133$ & $\chi 2 \Delta(1)=4.589, p=.032$ \\
\hline \multicolumn{5}{|l|}{$\mathrm{p}$ value } \\
\hline $\mathrm{R} 2$ individual level & & 2 & 1.7 & 2.1 \\
\hline R2 class level & & & 8 & 8.6 \\
\hline
\end{tabular}

Note. Level 1 predictors model includes age, gender, perceptions of unfair treatment and positive majority contact; Main effects model includes class composition: Interaction model includes interaction between perceptions of unfair treatment and positive majority contact 
Table S3. Relationship of positive majority contact and experiences of discrimination as predictors to majority and minority attitude and strength of identification as outcomes.

\begin{tabular}{|c|c|c|c|c|}
\hline & $\begin{array}{l}\text { Attitudes towards } \\
\text { majority }\end{array}$ & $\begin{array}{l}\text { Majority } \\
\text { identification }\end{array}$ & $\begin{array}{l}\text { Attitudes towards } \\
\text { minority }\end{array}$ & $\begin{array}{l}\text { Minority } \\
\text { identification }\end{array}$ \\
\hline \multicolumn{5}{|l|}{ INDIVIDUAL LEVEL } \\
\hline \multicolumn{5}{|l|}{ Positive majority } \\
\hline \multicolumn{5}{|l|}{ Experiences of } \\
\hline discrimination (DI) & $-5.82(1.29) * * *$ & $0.01(0.06)$ & $-4.13(1.34)^{* *}$ & $0.06(0.05)$ \\
\hline $\mathrm{CO} * \mathrm{DI}$ & $0.16(1.21)$ & $0.03(0.06)$ & $-2.61(1.14)^{*}$ & $-0.02(0.05)$ \\
\hline \multicolumn{5}{|l|}{ Control variables } \\
\hline Age & $0.81(0.58)$ & $0.03(0.03)$ & $-0.80(0.58)$ & $-0.02(0.03)$ \\
\hline Gender & $3.81(1.47)^{* *}$ & $0.35(0.08) * * *$ & $0.38(1.13)$ & $0.03(0.07)$ \\
\hline \multicolumn{5}{|l|}{ CLASS LEVEL } \\
\hline Composition & $-2.54(3.55)$ & $0.22(0.18)$ & $3.99(2.49)$ & $-0.10(0.18)$ \\
\hline \multicolumn{5}{|l|}{ EXPLAINED VARIANCE } \\
\hline $\mathrm{R}_{2}$ individual level & 15.9 & 13.1 & 4.8 & 1.7 \\
\hline $\mathrm{R}_{2}$ class level & 2.2 & 3.2 & 79.5 & 3 \\
\hline \multicolumn{5}{|l|}{ MODEL FIT } \\
\hline Deviance (-2LL) & 8755.35 & 3564.51 & 8267.73 & 3333.78 \\
\hline Akaike (AIC) & 8773.35 & 3582.51 & 8291.73 & 3351.78 \\
\hline Bayesian (BIC) & 8817.25 & 3627.46 & 8350.09 & 3396.39 \\
\hline Sample-Size Adjusted BIC & 8788.66 & 3598.87 & 8311.98 & 3367.81 \\
\hline
\end{tabular}


Table S4. Relationship of positive majority contact and experiences of discrimination as predictors to minority attitude and identification as outcomes controlling for minority contact.

\begin{tabular}{lll}
\hline & Attitudes towards minority & Minority identification \\
\hline & B (S.E.) & B (S.E.) \\
INDIVIDUAL LEVEL & & $-0.11(0.03)^{* * *}$ \\
Positive majority contact(CO) & $-0.85(0.47) \dagger$ & $0.05(0.05)$ \\
Experiences of discrimination (DI) & $-3.89(1.32)^{* * *}$ & $-0.02(0.04)$ \\
CO*DI & $-2.91(1.08)^{* *}$ & \\
Control variables & & $0.31(0.05)^{* * *}$ \\
Minority contact & $7.75(1.13)^{* * *}$ & $-0.05(0.03)$ \\
Age & $-1.05(0.57) \dagger$ & $0.06(0.07)$ \\
Gender & $1.20(1.08)$ & $-0.36(0.17)^{*}$ \\
CLASS LEVEL & & \\
Composition & $-1.92(2.41)$ & 3215.09 \\
MODEL FIT & & 3235.09 \\
Deviance (-2LL) & 8042.91 & 3284.48 \\
Akaike (AIC) & 8062.91 & 3252.72 \\
Bayesian (BIC) & 8111.37 & \\
Sample-Size Adjusted BIC & 8079.61 & \\
\hline
\end{tabular}

Table S5. Relationship of positive majority contact and perceptions of unfair treatment as predictors to minority attitude and identification as outcomes controlling for minority contact.

\begin{tabular}{lll}
\hline & $\begin{array}{l}\text { Attitudes towards } \\
\text { minority }\end{array}$ & $\begin{array}{l}\text { Minority } \\
\text { identification }\end{array}$ \\
\hline $\begin{array}{l}\text { INDIVIDUAL LEVEL } \\
\text { Positive majority contact(CO) }\end{array}$ & B (S.E.) & B (S.E.) \\
$\begin{array}{l}\text { Perceptions of unfair treatment } \\
\text { (FA) }\end{array}$ & $-1.94(0.53)^{* * *}$ & $-0.10(0.03)^{* *}$ \\
CO* FA & $1.72(0.57)^{* *}$ & $0.02(0.04)$ \\
Control variables & $1.10(0.46)^{*}$ & $0.05(0.03)^{\dagger}$ \\
minority contact & & \\
age & $5.61(0.93)^{* * *}$ & $0.31(0.05)^{* * *}$ \\
gender & $-0.68(0.57)$ & $-0.03(0.04)$ \\
CLASS LEVEL & $1.34(1.13)$ & $0.08(0.08)$ \\
Composition & & $-0.39(0.19)^{*}$ \\
MODEL FIT & $0.96(2.61)$ & 3461.67 \\
$\begin{array}{l}\text { Deviance (-2LL) } \\
\text { Akaike (AIC) }\end{array}$ & 8311.08 & 3481.67 \\
Bayesian (BIC) & 8331.01 & 3531.62 \\
Sample-Size Adjusted BIC & 8379.81 & 3499.86 \\
\hline
\end{tabular}


Table S6. Interaction model predicting minority attitude and identification as outcomes with positive majority contact and experiences of discrimination due to ethnic or religious origin as predictors

\begin{tabular}{|c|c|c|}
\hline & $\begin{array}{l}\text { Attitudes } \\
\text { minority }\end{array}$ & $\begin{array}{l}\text { Minority } \\
\text { identification }\end{array}$ \\
\hline & B (S.E.) & B (S.E.) \\
\hline \multicolumn{3}{|l|}{ INDIVIDUAL LEVEL } \\
\hline Positive majority contact(CO) & $-1.21(0.50)^{*}$ & $-0.12(0.04) * * *$ \\
\hline Experiences of discrimination (DI) & $-3.99(1.74)^{*}$ & $0.15(0.07)^{*}$ \\
\hline $\mathrm{CO} * \mathrm{DI}$ & $-3.34(1.33)^{*}$ & $-0.01(0.06)$ \\
\hline \multicolumn{3}{|l|}{ Control variables } \\
\hline age & $-0.58(0.62)$ & '-0.03 (0.04) \\
\hline gender & $0.12(1.14)$ & $0.05(0.08)$ \\
\hline \multicolumn{3}{|l|}{ CLASS LEVEL } \\
\hline Composition & $4.05(2.54)$ & $-0.08(0.18)$ \\
\hline \multicolumn{3}{|l|}{ MODEL FIT } \\
\hline Deviance (-2LL) & 7546.88 & 7546.88 \\
\hline Akaike (AIC) & 7564.88 & 7564.88 \\
\hline Bayesian (BIC) & 7607.83 & 7607.83 \\
\hline Sample-Size Adjusted BIC & 7579.25 & 7579.25 \\
\hline
\end{tabular}

Table S7. Reverse causation model predicting positive majority contact as outcome with attitudes towards minority and minority identification and experiences of discrimination as predictors.

\begin{tabular}{ll}
\hline \multicolumn{2}{l}{ Positive majority contact } \\
\hline B (S.E.)
\end{tabular}

INDIVIDUAL LEVEL

Attitudes towards minority (ATT) $-0.004(0.002)^{*}$

Minority identification (ID)

$-0.12(0.03)^{* * *}$

Experiences of discrimination (DI) $0.03(0.06)$

ATT*DI

$-0.003(0.002)$

$0.07(0.06)$

ID*DI

$-0.02(0.05)$

\section{Control variables}

age

gender

$-0.09(0.03)^{*}$

$-0.07(0.03)^{*}$

CLASS LEVEL

$-0.02(0.08) \quad-0.02(0.07)$

Composition

$-1.55(0.18) * * *$

$-1.44(0.19)^{* * *}$

MODEL FIT

Deviance (-2LL)

2965.36

3333.78

Akaike (AIC)

2983.36

3351.78

Bayesian (BIC)

3027.06

3396.39

Sample-Size Adjusted BIC

2998.48

3367.81 
Table S8. Reverse causation model predicting positive majority contact as outcome with attitudes towards minority and minority identification and perceptions of unfair treatment as predictors.

\begin{tabular}{lll}
\hline & \multicolumn{2}{l}{ Positive majority contact } \\
\hline INDIVIDUAL LEVEL & B (S.E.) & B (S.E.) \\
$\begin{array}{l}\text { Attitudes towards minority (ATT) } \\
\text { Minority identification (ID) }\end{array}$ & $-0.005(0.002)^{*}$ & \\
Perceptions of unfair treatment (FA) & $-0.22(0.21)$ & $-0.33(0.10)^{* * *}$ \\
ATT* FA & $0.003(0.002)$ & $0.014(0.034)$ \\
ID* FA & & \\
Control variables & & $0.06(0.03)^{*}$ \\
age & $-0.08(0.04)^{*}$ & $-0.06(0.03)^{*}$ \\
gender & $-0.03(0.08)$ & $-0.03(0.07)$ \\
CLASS LEVEL & & \\
Composition & $-1.55(0.18)^{* * *}$ & $-1.47(0.17)^{* * *}$ \\
MODEL FIT & & \\
Deviance (-2LL) & 3065,67 & 3925,68 \\
Akaike (AIC) & 3083.67 & 3943.68 \\
Bayesian (BIC) & 3127.64 & 3989.87 \\
Sample-Size Adjusted BIC & 3099.06 & 3961.28 \\
\hline
\end{tabular}

Table S9. Interaction model with all outcomes (majority attitude and identification and minority attitude and identification) included simultaneously with positive majority contact and perceptions of unfair treatment as predictors

\begin{tabular}{lllll}
\hline & $\begin{array}{c}\text { Attitudes } \\
\text { towards } \\
\text { majority }\end{array}$ & $\begin{array}{c}\text { Majority } \\
\text { identification }\end{array}$ & $\begin{array}{c}\text { Attitudes } \\
\text { towards } \\
\text { minority }\end{array}$ & $\begin{array}{c}\text { Minority } \\
\text { identification }\end{array}$ \\
\hline $\begin{array}{l}\text { INDIVIDUAL LEVEL } \\
\begin{array}{l}\text { Positive majority } \\
\text { contact(CO) }\end{array}\end{array}$ & $6.66(0.62)^{* * *}$ & $0.36(0.03)^{* * * *}$ & $-1.32(0.52)^{*}$ & -0.15 \\
$\begin{array}{l}\text { Perceptions of unfair } \\
\text { treatment (FA) }\end{array}$ & $2.46(0.71)^{* * *}$ & $0.12(0.05)^{* *}$ & $1.43(0.62)^{*}$ & $0.03(0.05)$ \\
$\begin{array}{l}\text { CO* FA } \\
\text { Control variables }\end{array}$ & $0.08(0.64)$ & $0.01(0.03)$ & $1.04(0.49)^{*}$ & $0.08(0.04)^{*}$ \\
$\begin{array}{l}\text { Age } \\
\text { Gender }\end{array}$ & $0.88(0.58)$ & $0.03(0.03)$ & $-0.39(0.59)$ & $-0.01(0.05)$ \\
CLASS LEVEL & $4.26(1.46)^{* *}$ & $0.33(0.08)^{* * *}$ & $0.41(1.15)$ & $0.04(0.10)$ \\
Composition & & & & \\
\hline
\end{tabular}

Note: Entries represent unstandardized coefficients (SE). ${ }^{*} p<.05, * * p<.01$ (2-tailed).

Gender: $0=$ male, $1=$ female 
Table S10. Interaction model with all outcomes (majority attitude and identification and minority attitude and identification) included simultaneously with positive majority contact and experiences of discrimination as predictors

\begin{tabular}{|c|c|c|c|c|}
\hline & $\begin{array}{l}\text { Attitudes } \\
\text { towards } \\
\text { majority }\end{array}$ & $\begin{array}{c}\text { Majority } \\
\text { identification }\end{array}$ & $\begin{array}{l}\text { Attitudes } \\
\text { towards } \\
\text { minority }\end{array}$ & $\begin{array}{c}\text { Minority } \\
\text { identification }\end{array}$ \\
\hline INDIVIDUAL LEVEL & $7.04(0.65)^{* * *}$ & $0.35(0.03)^{* * *}$ & $-1.37(0.50)^{* *}$ & $\begin{array}{l}-0.17 \\
(0.05) * * *\end{array}$ \\
\hline $\begin{array}{l}\text { Positive majority } \\
\operatorname{contact}(\mathrm{CO})\end{array}$ & $\begin{array}{l}-5.76 \\
(1.27) * * *\end{array}$ & $0.006(0.06)$ & $-4.11(1.32)^{* *}$ & $0.03(0.07)$ \\
\hline $\begin{array}{l}\text { Experiences of } \\
\text { discrimination (DI) } \\
\text { CO*DI }\end{array}$ & $-0.003(1.12)$ & $0.03(0.06)$ & $-2.65(1.15)^{*}$ & $0.008(0.06)$ \\
\hline Control variables & & & & \\
\hline Age & $0.83(0.59)$ & $0.03(0.03)$ & $-0.71(0.60)$ & $-0.02(0.05)$ \\
\hline Gender & $4.01(1.48)^{* *}$ & $0.35(0.08)^{* * *}$ & $0.19(1.14)$ & $0.02(0.10)$ \\
\hline $\begin{array}{l}\text { CLASS LEVEL } \\
\text { Composition }\end{array}$ & $-2.72(3.57)$ & $0.24(0.19)$ & $3.21(2.54)$ & $-0.26(0.25)$ \\
\hline
\end{tabular}

Note: Entries represent unstandardized coefficients (SE). $* p<.05, * * p<.01$ (2-tailed).

Gender: $0=$ male, $1=$ female 
Figure S1. Attitudes towards the minority at low (-1 SD) and high (+1 SD) levels of experiences of discrimination and low (-1 SD) and high (+1 SD) amount of positive majority contact controlling for minority contact

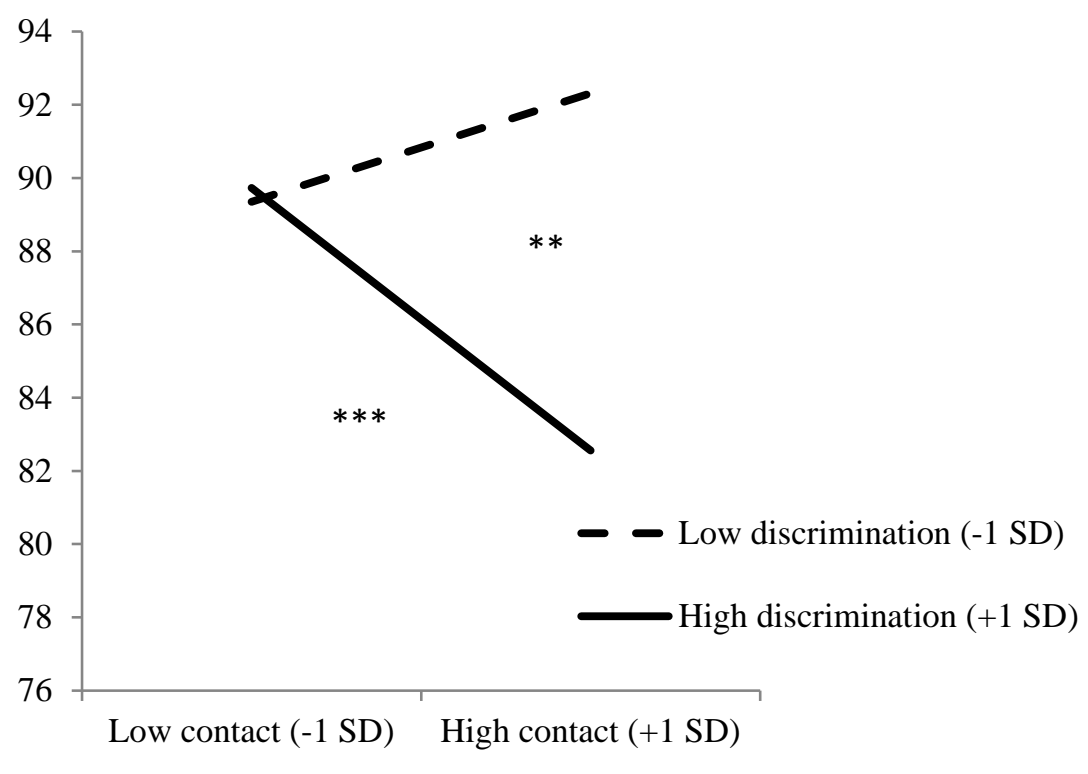

Figure S2. Attitudes towards the minority at low (-1 SD) and high (+1 SD) levels of perceptions of unfair treatment and low (-1 SD) and high (+1 SD) amount of positive majority contact controlling for minority contact

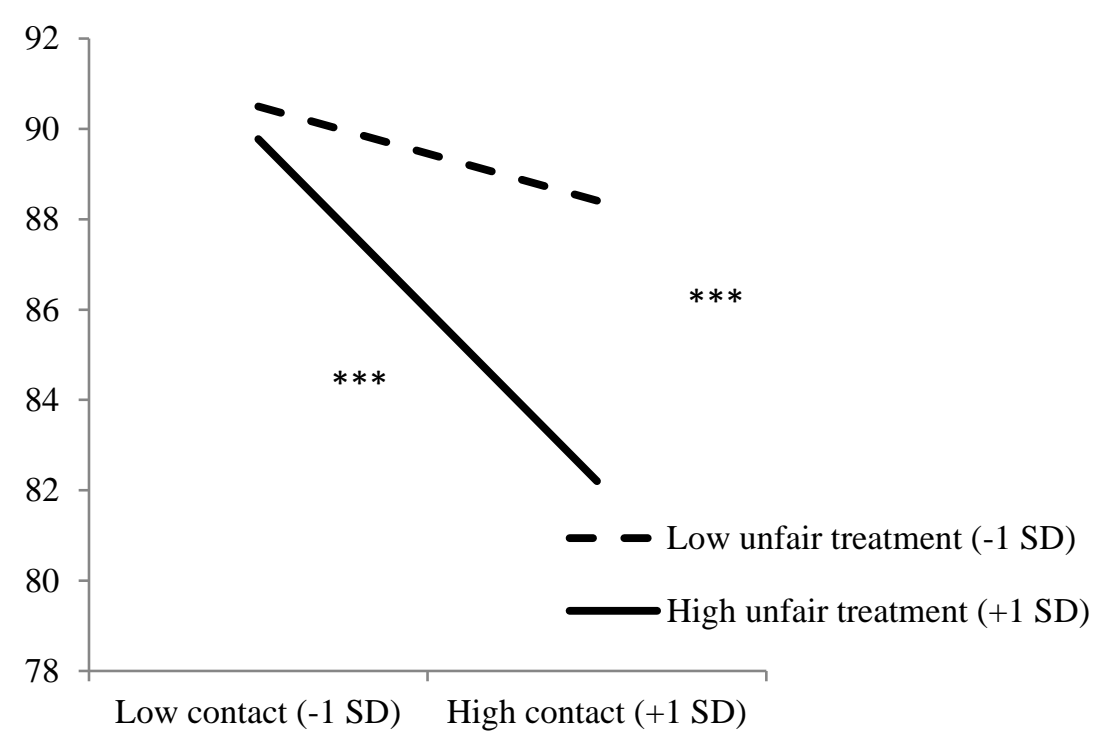


Figure S3. Ethnic identification at low (-1 SD) and high (+1 SD) levels of perceptions of unfair treatment and low (-1 SD) and high (+1 SD) amount of positive majority contact controlling for minority contact

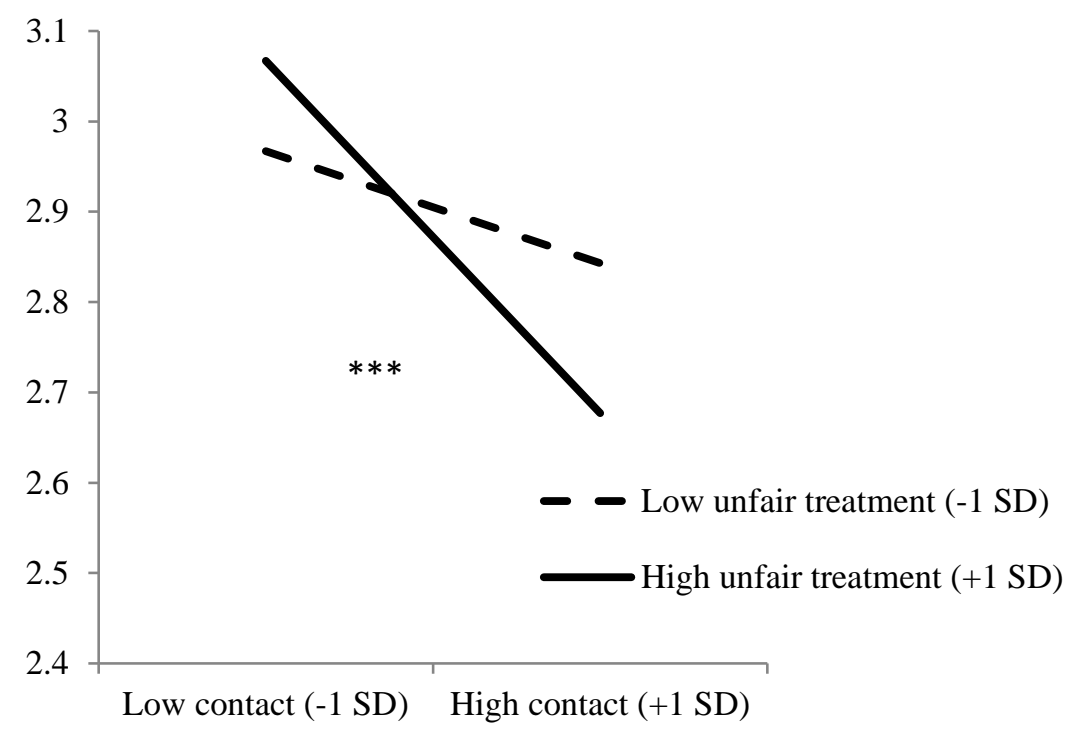

Figure S4. Attitudes towards the minority at low (-1 SD) and high (+1 SD) levels of discrimination explicitly due to ethnic or religious origin and low (-1 SD) and high (+1 SD) amount of positive majority contact controlling for minority contact

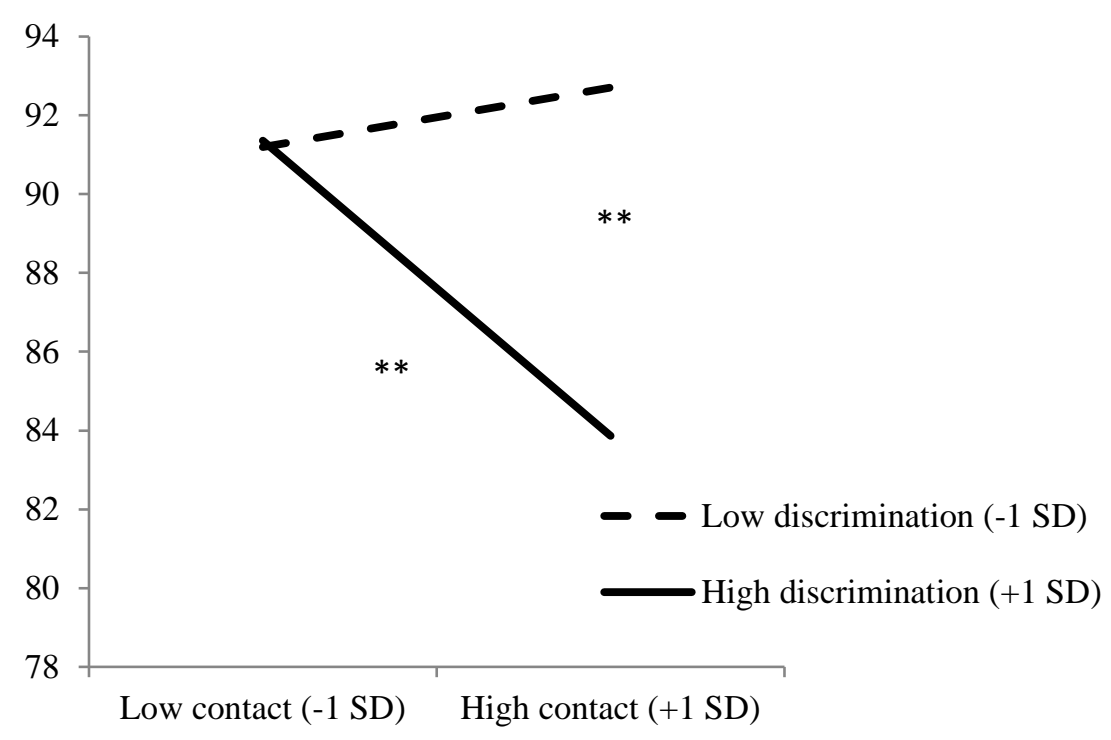

